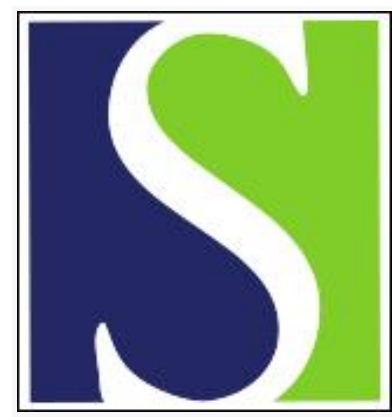

Scand J Work Environ Health 2007;33(6):405-424

https://doi.org/10.5271/sjweh.1171

Issue date: 31 Dec 2007

Occupational physical activity, energy expenditure and 11-year progression of carotid atherosclerosis

by Krause N, Brand RJ, Kaplan GA, Kauhanen J, Malla S, Tuomainen T-P, Salonen JT

Affiliation: University of California at San Francisco, UC Berkeley Richmond Field Station, 1301 South 46th St, Bldg 163, Richmond CA 94804, USA.nkrause@berkeley.edu

Refers to the following texts of the Journal: $2000 ; 26(3): 227-236$ 2002;28(1):25-32

The following articles refer to this text: $2007 ; 33(6): 401-404$; 2009;35(6):466-474; 2010;36(1):62-70; 2010;36(5):357-365; 2010;36(5):366-372; 2010;36(5):349-355; 2011;37(1):6-29; 2010;36(6):466-472; 2012;38(4):370-379; 2012;38(5):467-475; 2015;41(2):140-152; 2015;41(2):124-139; 2016;42(3):237-245; 2016;42(4):291-298; 2016;42(5):423-434; 2019;45(3):267-279; 2020;46(2):188-197; 2022;48(2):86-98; 2023;49(3):231-244

Key terms: behavioral factor; caloric job demand; cardiorespiratory fitness; cardiovascular disease; carotid atherosclerosis; coronary heart disease; energy expenditure; hemodynamic theory of atherosclerosis; occupational physical activity; physical workload; prospective study; relative aerobic strain; relative oxygen uptake reserve

This article in PubMed: www.ncbi.nlm.nih.gov/pubmed/18327509 


\title{
Occupational physical activity, energy expenditure and 11-year progression of carotid atherosclerosis
}

\author{
by Niklas Krause, MD, ${ }^{1}$ Richard J Brand, PhD, ${ }^{2}$ George A Kaplan, PhD, ${ }^{3}$ Jussi Kauhanen, MD, ${ }^{4}$ Smriti \\ Malla, MSc, ${ }^{1}$ Tomi-Pekka Tuomainen, MD, ${ }^{4}$ Jukka T Salonen, MD ${ }^{4,5}$
}

\begin{abstract}
Krause N, Brand RJ, Kaplan GA, Kauhanen J, Malla S, Tuomainen T-P, Salonen JT. Occupational physical activity, energy expenditure and 11-year progression of carotid atherosclerosis. Scand J Work Environment \& Health. 2007;33(6):405-424.
\end{abstract}

Objectives This study prospectively assessed the effects of occupational physical activity on atherosclerosis progression.

Methods This population-based prospective study of ultrasonographically assessed carotid intima media thickness (IMT) used repeated measures of occupational physical activity during baseline, 4-year, and 11-year examinations of 612 Finnish men 42-60 years of age at baseline. The association between five measures of energy expenditure and the 11-year change in maximum IMT was evaluated in regression models adjusting for 21 potential confounders, including biological factors, leisure-time physical activity, smoking, socioeconomic status, psychosocial job factors, and baseline health status.

Results At baseline, $31 \%$ of all the men and $51 \%$ of those with ischemic heart disease (IHD) exceeded the recommended maximum levels of relative aerobic strain. All five measures of energy expenditure were significantly associated with adjusted 11-year IMT change. Significant interactions were found between IHD and several measures of energy expenditure. Maximum relative aerobic strain resulted in a 90\% increase in IMT among the men with IHD compared with a $46 \%$ increase among those without IHD. The men with preexisting carotid stenosis also had higher rates of IMT progression than the men without this condition.

Conclusions This study shows that high energy expenditures at work are associated with an accelerated progression of atherosclerosis even after control for virtually all known cardiovascular risk factors, especially among older workers and workers with preexisting IHD or carotid artery stenosis. The findings support the hemodynamic theory of atherosclerosis and have important implications for workplace surveillance and disease prevention.

Key terms behavioral factor; caloric job demand; cardiorespiratory fitness; cardiovascular disease; coronary heart disease; hemodynamic theory of atherosclerosis; physical workload; prospective study; relative aerobic strain; relative oxygen uptake reserve.

In contrast to leisure-time physical activity, little is known about the cardiovascular disease (CVD) risks and benefits associated with occupational physical activity. Most epidemiologic studies to date either failed to differentiate between leisure-time physical activity and occupational physical activity or excluded occupational physical activity from their analyses altogether (1-4). While the beneficial effects of leisure-time physical activity on the circulatory system are relatively well established, the literature about the health effects of occupational physical activity remains inconsistent (5). Higher levels of occupational physical activity were associated with a reduced risk of CVD in some prospective population-based studies (6-11), showed no association in others $(7,12,8,13-17)$, or were associated with an increased CVD risk (18-21). A few studies showed

1 Department of Medicine, Division of Occupational and Environmental Medicine, University of California at San Francisco, San Francisco, California, United States.

2 Department of Epidemiology and Biostatistics, University of California, California at San Francisco, San Francisco, California, United States.

3 Department of Epidemiology, Center for Social Epidemiology and Population Health, University of Michigan, Ann Arbor, Michigan, United States.

4 School of Public Health and Clinical Nutrition, University of Kuopio, Kuopio, Finland.

5 Oy Jurilab Ltd, Kuopio, Finland.

Correspondence to: Dr N Krause, University of California at San Francisco, UC Berkeley Richmond Field Station, 1301 South 46th St, Bldg 163, Richmond CA 94804, USA. [E-mail: nkrause@ berkeley.edu] 
differential effects, leisure-time physical activity being protective and occupational physical activity having no effect $(17,22)$, leisure-time physical activity having an effect only among persons with low levels of occupational physical activity (11), or leisure-time physical activity constituting a CVD risk (19).

Most studies used only crude categorical measures of occupational physical activity and did not assess changes in occupational physical activity during follow-up. The few studies that used a continuous measure of energy expenditure did not adjust for individual aerobic fitness, which determines the actual cardiovascular load at any given caloric job demand. In addition, only one study adjusted for psychosocial job factors (20), although job stress has been found to be an important risk factor for CVD in several studies (23-27) and could confound associations between occupational physical activity and CVD. Such limitations may be responsible for the inconsistent findings in the literature. The current study was designed to address these methodological issues by (i) using a validated interview instrument to assess occupational physical activity at baseline and repeatedly during 11 years of follow-up, (ii) using continuous rather than categorical exposure measures, (iii) supplementing absolute with relative measures of energy expenditure (relative aerobic strain, percentage of oxygen uptake reserve), and (iv) by adjusting for a comprehensive set of 21 possible confounders including virtually all known biological, behavioral, and psychosocial risk factors.

Furthermore, this study circumvents the thorny issue of selection due to the so-called healthy worker effect by using the change in carotid intima media thickness (IMT) as the outcome measure instead of CVD symptoms or clinical events. Workers with impaired health often migrate into less demanding jobs, and this migration could lead to a spurious association between little occupational physical activity and morbidity or mortality outcomes. Ultrasound measurements in asymptomatic populations allow an examination of the relationship between work characteristics and atherosclerosis before disease-based selection effects occur $(28,29)$. Ultrasound measurement of IMT in the carotid arteries has been shown to be reliable, to relate to the extent of disease in the coronary arteries, and to have predictive validity with regard to the risk of coronary events $(30,31,29,32)$.

Building on the hemodynamic theory of atherosclerosis (33), this study used a biological model of disease causation that rests on established hemodynamic changes triggered by physical activity and an increased heart rate, resulting in changes in intravascular turbulence and wall shear stress causing injury and inflammatory processes in the arterial wall that manifest as atherosclerosis (20). Specifically, an increased heart rate shortens the cumulative time spent in systole when wall shear stress is optimal and leads to more time spent in diastole when wall shear stress fluctuates in a suboptimal range (33). Increased turbulence and the resulting reduction in shear stress at the arterial walls are considered some of the main hemorheologic phenomena that induce endothelial damage in human arteries $(34,33,35)$. Such endothelial damage sets the stage for the absorption of lipids and other pathogenic substances and cells into the arterial wall, leading to an inflammatory process currently believed to be the basis of IMT, the formation of atherosclerotic plaques, and eventual stenosis of the arteries (36). Progression of lumen-reducing stenosis in turn will lead to suboptimal poststenotic wall shear stress because wall shear stress is an exponential function of vessel radius. These mechanisms were proposed as an explanation for the previously observed higher rate of progression of atherosclerosis associated with a standing work posture for people with preexisting beginning stenosis when compared with people without preexisting stenosis (20).

Reduced cardiorespiratory fitness due to a lack of training or preexisting ischemic heart disease (IHD) has also been associated with the progression of atherosclerosis (37). Again, the hemodynamic theory of atherosclerosis would explain this association through disproportional elevated heart rates when these persons engage in demanding physical activities. On the other hand, engagement in physical activity can be expected to have a training effect that could lead to lower heart rates during daily activities and rest and thereby decelerate the progression of atherosclerosis. Therefore, two-sided statistical tests need to be applied in the study of the effect of occupational physical activity on atherosclerosis.

In accordance with the hemodynamic theory of atherosclerosis, four hypotheses were tested in this investigation. After taking leisure-time physical activity and other individual behavioral and biological risk factors, as well as psychosocial job factors, into account, we hypothesized that the progression of atherosclerosis is associated with (i) absolute levels of energy expenditure at work and (ii) relative levels of energy expenditure (relative aerobic strain and the percentage of oxygen uptake reserve). Furthermore, we hypothesized that (iii) any association of occupational physical activity with the progression of atherosclerosis is stronger in people with preexisting IHD or with (iv) preexisting carotid stenosis.

\section{Study population and methods}

\section{Study population}

The participants were Finnish men 42-60 years of age at baseline who participated in the Kuopio Ischemic 
Heart Disease Risk Factor Study, a prospective population-based investigation of established and potential risk factors for heart disease and extracoronary atherosclerosis. Details of the study design have been published elsewhere $(38,37)$. In all, 2682 men who resided in the town of Kuopio or its surrounding rural communities in eastern Finland participated in the study. Baseline data were collected for two cohorts, a random sample of 1166 men aged 54 years, initiated in March 1984, and an age-stratified random sample of 1516 men aged 42, 48,54 , or 60 years (participation rate $78 \%$ ), initiated in August 1986 .

Ultrasound measurements of IMT in the common carotid arteries were conducted beginning in March 1987 on 1229 men in the second cohort. These 1229 men were invited to participate in a follow-up assessment approximately 4 years after the baseline examination. By that time, 47 had died or were suffering severe illness, 37 had moved or could not be contacted, and 107 refused, leaving 1038 participants (participation rate $84.5 \%$ ). Of these, 1007 men were alive prior to the start of a follow-up 11 years after the baseline examination. Follow-up examinations were scheduled between March 1998 and February 2001. During this time, 58 more men died before being examined, 38 had a severe illness, 27 had moved or could not be contacted, 25 refused, and 5 did not participate for other reasons, leaving 854 participants in the 11-year follow-up (participation rate $84.8 \%)$.

Of the 854 participants in the 11-year follow-up, 223 were excluded because they had not worked at all between the baseline examination and the 11-year follow-up, 2 because they did not participate in the 11year ultrasound examination, 2 because of unnreliable information on worktime (they had reported working 24 hours during their last workday and no alternative information on typical workhours was available for them), and 15 because of missing values on one or more of the exposure variables, leaving 612 men for the analyses. Missing values for one or more of the covariates had been replaced by sample mean values for 11 (ie, less than $1.8 \%$ of the observations). The follow-up time between the ultrasound examinations ranged from 9.23 to 13.82 (mean 11.13 ) years.

\section{Assessment of atherosclerotic progression}

Measurements of IMT were taken at approximately 100 sites along a 1.0- to $1.5-\mathrm{cm}$ section of both the left and right common carotid artery below the carotid bulb using high-resolution B-mode ultrasonography. Measurements were made with the participants supine and the image focused on the posterior (far) wall. Additional technical details have been published elsewhere (29). IMT was measured as the distance from the leading edge of the first echogenic line to the leading edge of the second echogenic line. Maximum IMT was defined for the participants as the average of the maximum IMT values from the right and left common carotid arteries. The maximum narrowing of the lumen is the most relevant for arterial flow changes according to the hemodynamic theory. Our outcome measure was defined as the natural $\log$ of the maximum IMT at 11 years minus the natural $\log$ of the maximum IMT in the baseline examination. The reliability of the baseline and longitudinal ultrasonic measurements of carotid IMT is high $(39,40,32)$.

\section{Assessment of occupational physical activity}

An interview on occupational physical activity was administered by trained interviewers at the baseline and at the 4-year and 11-year follow-ups to the men who had worked at least some time in the past 12 months. The interview addressed a typical workday. The participants were asked, with an accuracy of 15 minutes, how long they had performed the following activities at work: sitting, standing, walking on level ground, walking on uneven ground, climbing stairs, or any other activities. The 12-month test-retest correlations for the occupational activity interview was found to be 0.69 , indicating good reliability for the instrument (41). The lifetime job stability of people living in the Kuopio region is relatively high (42), and therefore the probability of misclassifying work activities between the follow-up examinations was reduced.

A self-administered questionnaire was also completed at the baseline, the 4-year follow-up, and the 11-year follow-up; it provided information on work status (full-time work, part-time work, unemployment, retirement, not working for another reason). Those not currently working were asked about the year when an unemployment or retirement period began, the number of days worked per week in the last job, and the number of hours worked per day. For those working, workdays per week, the number of hours and minutes worked per day, and the number of days they missed work due to illness during the past 12 months were assessed.

The data from the self-administered questionnaire and interview on occupational physical activity were linked to the pension registers of the social insurance institution and the central pension security institute of Finland, covering all old-age, disability, and early retirement pensions of the participants from baseline through the end of May 2000. These administrative retirement data were used to obtain more exact retirement dates (month and year rather than just year) for the men who reported they had retired between the follow-up surveys. Occupation was assessed with a questionnaire and 3digit code according to the Finnish Classification of Occupations of Tilastokeskus (Statistics Finland). 


\section{Measures of energy expenditure}

We estimated energy expenditure at work by using the interview data on time spent in various activities at work and combined this information with reference data giving the energy requirements [kcal/(kg.hour)] of these activities.

This method was used at baseline and in the 4- and 11-year follow-up surveys. In addition, cardiorespiratory fitness and the weight of the participants were measured at baseline. Other basic data were the number of days worked per week at each examination time and the dates of the ultrasound examinations. Finally, information about sick leave (only for the 12 months preceding the follow-up surveys), unemployment, and retirement (both for the entire follow-up period) were obtained to estimate the actual time spent working during each follow-up segment. These basic measurements provided the data for constructing five measures of energy expenditure at work that were used as predictors in this report. We first describe the basic measurement of energy expenditure per typical workday at each examination and the determination of cardiorespiratory fitness. Then we describe the five measures of work-related energy expenditure in more detail.

\section{Energy expenditure per typical workday at baseline and} after 4 and 11 years of follow-up. Energy expenditure reflects the duration and intensity of each type of occupational physical activity. The duration (hours/typical day) of different physical activities at work was assessed in an occupational interview. The energy requirement of these activities was estimated as multiples of the baseline metabolic rate (MET) in kilocalories/(kg.hour) of an average male with values of 1.6 for work while sitting, 2.4 for standing, 3.3 for walking on level ground, 4.9 for walking on uneven ground, 7.3 for climbing stairs, and a mean value of 3.9 for other unspecified activities on the basis of previously published data $(43,44)$. Energy expenditure in kilocalories for each reported activity was calculated by multiplying the duration (hours per day) by the respective intensity (MET) and body weight $(\mathrm{kg})$ of the person. The sum of these estimates gives the energy expenditure measured in kilocalories per typical workday. These measures were obtained at baseline and in the 4-year and 11-year follow-up interviews.

Cardiorespiratory fitness at baseline. Cardiorespiratory fitness (aerobic capacity or maximal oxygen uptake) was assessed by a maximal but symptom-limited exercise test on an electrically braked ergometer as explained in detail elsewhere $(45,37,46)$. Oxygen consumption was measured using an analysis of respiratory gas exchange. Maximal oxygen uptake $\left(\mathrm{VO}_{2} \max \right)$ was defined as the highest value or the plateau in oxygen uptake and was standardized by body weight and measured as milliliters of oxygen per kilogram per minute.

Using the basic data already presented, the following five measures of work-related energy expenditure were constructed and used as predictors of the carotid artery changes during follow-up: (i) energy expenditure per typical workday at baseline, (ii) total amount (volume) of energy expenditure at work during 11 years of followup, (iii) energy expenditure per potential 8-hour standard workday during follow-up, (iv) relative aerobic strain $\left(\% \mathrm{VO}_{2} \max \right)$ at baseline and (v) percentage of oxygen uptake reserve $\left(\% \mathrm{VO}_{2} \mathrm{Res}\right)$.

Energy expenditure per typical workday at baseline is simply the baseline assessment of energy expenditure per typical workday according to the described method. It does not take account of any changes in the duration or mix of activities during the follow-ups, nor does it account for such things as periods of unemployment or the termination of work due to retirement. In contrast, the following measure does take such changes into account.

Total work-related energy expenditure was first calculated separately for the two follow-up segments, 0 4 years and 4-11 years, and their results were added to get the result for the full follow-up period of 0-11 years. The first step in these calculations was to determine the number of calendar days (including weekends) during each of the two follow-up segments defined by dates of the "bracketing" ultrasound measurements. The total work-related calendar time in each segment was reduced by vacation, unemployment, sick leave, and retirement. Then, in each segment, the resulting actual duration of worktime (in calendar days) was multiplied by the average of the energy expenditures (kilocalories/calendar day) at the beginning and end of the segment. At each examination time, kilocalories/calendar day was obtained by multiplying the energy expenditure per typical workday by the number of workdays per week divided by 7 . This latter factor distributed the energy expended in the workweek over the 7-day calendar week.

Energy expenditure per potential 8-hour standard workday during the follow-up is the ratio of the total energy expended during the actual worktime from baseline to 11 years divided by the calendar time during which the participant could potentially have worked during the follow-up period [assuming regular standard 8-hour workdays, 5-day workweeks, and 46 workweeks per year (representing the Finnish standard 1840 workhours per year)]. In other words, total energy expenditure during the follow-up is expressed as an intensity measure calibrated to available standard workdays during the same period. If each participant had worked the standard worktime between the baseline and their final follow-up examination, this measure would be perfectly correlated with the total work-related energy expenditure during 
11 years of follow-up. It differs from that measure by accounting for some person-to-person variation in the typical length of their workdays, workweeks, and duration of employment during the follow-up. In contrast to relative measures of energy expenditure taking cardiorespiratory fitness into account (described next), this measure takes into account the potentially available number of regular standard workdays between the ultrasound examinations for each person.

Relative aerobic strain $\left(\% \mathrm{VO}_{2} \max \right)$ is a relative energy expenditure measure that expresses the caloric demands of work as a percentage of the individual worker's aerobic cardiorespiratory fitness or maximal work capacity (47). It has traditionally been used to define recommended maximum levels of aerobic work demands. The assessment of $\% \mathrm{VO}_{2}$ max was based only on the measurement obtained at baseline since this was the only examination time for which data on maximal oxygen uptake were generally available.

The percentage of oxygen uptake reserve is an alternative relative energy expenditure measure that expresses the caloric demands of work in relation to the individual workers' aerobic cardiorespiratory fitness or maximal work capacity as a percent of oxygen uptake reserve $\left(\% \mathrm{VO}_{2}\right.$ Res) (48). While $\% \mathrm{VO}_{2}$ max is based on the total energy expenditure at work, including the energetic cost of metabolic rate for both rest and work activity, $\% \mathrm{VO}_{2}$ Res is based on the energy expenditure associated with the work activity only and is measured as $\% \mathrm{VO}_{2} \mathrm{Res}=\left(\mathrm{VO}_{2}\right.$ work -3.5$) /\left(\mathrm{VO}_{2} \max -3.5\right) \times 100 \%$ because the resting energy expenditure is $1 \mathrm{MET}=3.5$ $\mathrm{ml} \mathrm{O} /(\mathrm{kg} \cdot$ minute $)(49,48)$. In our study, $\mathrm{VO}_{2}$ work was determined by calculating the weighted average of MET during work activities based on the occupational interview multiplied by $3.5 \mathrm{ml} /(\mathrm{kg} \cdot$ minute). Recently, $\% \mathrm{VO}_{2} \mathrm{Res}$ has been suggested as the preferred measure of relative energy expenditure for use in job analyses and epidemiologic field studies because it allows for more adequate comparisons than $\% \mathrm{VO}_{2}$ max does when the energy expenditure varies greatly in the study population. A further advantage of this measure is the fact that, in contrast to $\% \mathrm{VO}_{2} \max , \% \mathrm{VO}_{2}$ Res corresponds directly to the percentage of heart rate reserve that can be measured more easily in the field than the $\% \mathrm{VO}_{2} \mathrm{Res}$ itself (48).

Proportion of workers exceeding the recommended maximum level of aerobic strain at work. A maximum relative aerobic strain of $33 \% \mathrm{VO}_{2}$ max has traditionally been recommended as a safe level of aerobic work demands for a typical 8-hour workday on the basis of the physiological criteria of a steady state of blood lactate or heart rate $(50,51)$. However, no widely accepted recommendations are available for non-8-hour workshifts, to which an increasing proportion of workers is being exposed. Rogers et al (50) adapted the 8-hour standard to 4-, 10-, and 12-hour workshifts. A recent laboratory study by $\mathrm{Wu}$ \& Wang (52) among seven young males suggests that the recommendations need to be adjusted upward to $34 \%$ for 8 hours, further upward to about $43.5 \%$ for a 4 -hour day, and downward for longer shifts to about $28.5 \%$ for a 12-hour day on the basis of a steady-state heart rate plus maximal 10 beats at the end of the work period as the criterion for sustainable maximal work effort. However, empirical laboratory data were not gathered beyond 10-hour periods, and extrapolation to longer shifts may be problematic. One of the features of $\mathrm{Wu}$ \& Wang's exponential function, used to fit the data, is that maximum allowable $\% \mathrm{VO}_{2} \max$ is not substantially reduced for workshifts that exceed 8 hours. For example, the result of $34 \%$ for $\% \mathrm{VO}_{2}$ max for an 8-hour workday changes to $32.4 \%, 31 \%, 29.7 \%, 28.5 \%, 27.4 \%, 26.4 \%$, $25.4 \%$, and $24.5 \%$ for workdays equal to $9,10,11,12$, $13,14,15$, and 16 hours, respectively. These limited reductions for longer workshifts seem somewhat implausible, but, unfortunately, the literature does not provide an empirically based alternative to this extrapolation outside of the range of the empirical data used by $\mathrm{Wu} \&$ Wang to construct the formula. In acknowledgement of these uncertainties, we present the proportion of workers exceeding recommended levels of energy expenditure according to two assessment methods, the first with the assumption that all men work standard 8-hour days and the second with adjustment for length of workdays based on Wu \& Wang's results.

\section{Assessment of covariates}

The 21 covariates used in the multivariate analyses can be grouped into the following five categories: (i) age and technical factors (participation in an unrelated lipidlowering trial, baseline maximum IMT values, physician performing 11-year sonography (all baseline ultrasounds conducted by the same person), (ii) biological factors (blood glucose, fibrinogen, serum low-density lipoprotein (LDL) cholesterol, serum high-density lipoprotein (HDL) cholesterol, use of cholesterol-lowering medication, systolic blood pressure, use of blood-pressurelowering medication, body mass index), (iii) behavioral factors (alcohol use, smoking, conditioning leisure-time physical activity, and cardiorespiratory fitness); (iv) socioeconomic status measured by personal income, and (v) psychosocial work-related factors (social support from co-workers or supervisors, stress from work deadlines, and mental strain at work). Socioeconomic status, psychosocial work factors, and all of the behavioral factors except cardiorespiratory fitness were assessed by self-administered questionnaires at baseline and at the 4-year and 11-year follow-ups. A complete list of covariates and their distribution is provided in appendix A. Details of the measurement of these variables have 
been described previously $(53,54)$. In the following, we give a short summary of the measurement of some of the key covariates.

Blood pressure was measured with a random-zero sphygmanometer after 5 minutes of rest in a supine position. Three measurements were then taken while the participant was still supine, one while standing, and two while sitting, in that order. The average of these six measurements was used in our analyses. Body mass index (BMI) was defined as weight in kilograms divided by height in meters squared at baseline. The use of cholesterol- and blood-pressure-lowering medications was assessed by a questionnaire.

Alcohol consumption in grams per week during the past 12 months was assessed with a structured quantity-frequency method using the Nordic Alcohol Consumption Inventory (55). Cigarette use was a fourlevel categorical variable (never smoker, former smoker, irregular smoker, regular smoker). In the preliminary analyses, tertiles of regular smoking were used. The tertiles were then collapsed into one category ("current smoker") because the effect sizes were very similar for these tertiles, and the confidence intervals overlapped widely. Conditioning leisure-time physical activity, in hours per year, was measured using a modified version of the Minnesota Leisure Time Physical Activity questionnaire (56) that included the 16 most common leisure-time physical activities of middle-aged Finnish men (43). The respondents were asked to estimate the duration, frequency, and intensity of each of 16 activities performed for each of the 12 previous months. Hours of conditioning physical activities with a mean intensity of 6.0 MET have been associated with a decreased risk of myocardial infarction in this cohort (45). Cardiorespiratory fitness $\left(\mathrm{VO}_{2} \mathrm{max}\right)$, based on respiratory gas exchange, was measured as milliliters per kilogram per minute by a maximal symptom-limited bicycle ergometer test at baseline (45).

Socioeconomic status was measured by personal income in Finnish marks, social support at work from co-workers and supervisors was measured by several standard items, stress from work deadlines was measured by one item, and a 10-item mental-strain index measured job stress as described previously (54).

For most of the continuous predictors, averages of the baseline, 4-year, and 11-year values were used in all of the regression models. For the continuous variables that have previously been linked to CVD outcomes and that are known to be influenced by physical activity (HDL, LDL, BMI, and $\mathrm{VO}_{2} \mathrm{max}$ ) only the baseline values were used in order to avoid overadjustment for occupational physical activity measured during the course of the follow-up. There may still have been some overadjustment because the baseline values partly reflect past occupational exposures that are often highly correlated with current exposures. For cholesterol- and blood-pressure-lowering medications, the analyses used the proportion of examinations when medication use was reported.

\section{Assessment of cardiovascular health at baseline}

Ischemic heart disease. The participants with existing IHD at baseline were those who (i) had a history of prior myocardial infarction or angina pectoris, (ii) currently used anti-angina medication, or (iii) had positive findings of angina according to the London School of Hygiene cardiovascular questionnaire (57).

Carotid artery stenosis. Baseline IMT recordings were classified by one physician, blind to other measures, into the following four categories: (i) no atherosclerotic lesion, (ii) IMT, (iii) nontenotic plaque, and (iv) large stenotic plaque. IMT (category 2) was defined as more than $1 \mathrm{~mm}$ between the lumen-intima interface and the media-adventitia interface in the common carotid arteries below the bulb. Nonstenotic plaque was defined as a distinct area of mineralization of focal protrusion into the lumen. A plaque was defined as stenotic if it obstructed more than $20 \%$ of the lumen diameter, and this definition constituted carotid artery stenosis in this study (29). The participants were not informed about these ultrasound results except for a limited number of examinees who were judged to require medical attention.

\section{Statistical methods}

The baseline characteristics of the men with and without cardiovascular disease (IHD or carotid stenosis) were compared using t-tests for continuous variables and chisquare tests for categorical variables.

To study the progression of maximal intima media thickness (maxIMT) over 11 years of follow-up, we used a multiple linear regression analysis implemented in Stata 9.1 (Stata Corporation, College Station, TX, USA). The outcome for these analyses was $\left[\ln \left(y_{F}\right)-\ln \left(y_{I}\right)\right] / \Delta t$, where $y_{I}$ is the initial maxIMT at baseline and $y_{F}$ is the final maxIMT in the follow-up examination $\Delta t$ years after the baseline examination. The maxIMT values at baseline and the follow-up were ln-transformed because this procedure normalized the original skewed maxIMT measurements. In addition, the residual distribution of the changes in $\ln (\max I M T)$ was more nearly normal than changes based on maxIMT without transformation. The division by $\Delta t$ handles variation from the nominal follow-up time of 11 years by expressing change on a per-year basis. In these analyses, we included a predictor based on a measure of energy expenditure along with some or all of the 21 covariates listed in appendix A. Continuous covariates were centered at the mean if they had no natural interpretation of zero values. 
The use of changes the in ln-transformed maxIMT leads naturally to an interpretation of the results in terms of relative change and the percentage of change. Relative change is $\mathrm{RC}=y_{F} / y_{I}$, and note that $\left[\ln \left(y_{F}\right)-\ln \left(y_{I}\right)\right] /$ $\Delta t=\ln \left(y_{F} / y_{I}\right) / \Delta t=\ln (R C) / \Delta t$. Consequently, for any specified values of the predictors, the fitted model provides a way to estimate average $\ln (R C) / \Delta t$, symbolized as $E[\ln (R C) / \Delta t]$. A corresponding estimate of $E[R C]$ over $K$ years instead of per year is obtained from $E[R C]_{K}=\phi \exp (E[\ln (R C)] K / \Delta t)$, where $\phi$ is the back-transformation correction factor, which, with our data, was so close to 1 that it had no effect. Correspondingly, the average percentage of change for $K$ years, $E[P C]_{K}=100\left(E[R C]_{K}-1\right)$.

Several tables present the estimated expected average of the percentage of change for 11 years using the coefficients from the fitted model. We calculated the estimated relative change for the minimum, median, and maximum value, for each energy expenditure measure. Other variables were set to zero, which corresponds to using the mean value for centered continuous variables, and the reference level coded 0 for any predictor was used to represent categorical variables. We also studied whether or not the association between the energy variable and the outcome differed for the subgroups with and without IHD at baseline. Similar subgroup-specific results were examined for the subgroups with and without carotid stenosis at baseline.

The relative change ratio (RCR), defined as the ratio of the relative change at a comparison level of a predictor of interest divided by the relative change at a reference level for the predictor, provides a summary measure of the association between an energy measure, $x_{1}$, and the outcome. The RCR depends on the years of follow-up $(K)$. With a multiple regression model, $E[\ln (R C) / \Delta t]=B_{0}+B_{1} x_{1}+\ldots+B_{p} x_{p}$, in which there are no interaction terms involving the predictor, $x_{1}$, the RCR for $K$ years of follow-up is $R C R=\exp \left(B_{1} \Delta_{1} K\right)$, where $\Delta_{1}=x_{l}^{C}-x_{l}^{R}$ is the difference between the comparison level and the reference level for the predictor, $x_{1}$.

To check the adequacy of a simple linear representation of the energy expenditure variables, we assessed whether a significantly improved fit resulted from using both linear and quadratic terms in the fully adjusted model. Models without the quadratic term were not rejected in favor of those with the quadratic terms.

\section{Results}

\section{Characteristics of the study population}

At baseline, the average age was 49.5 (SD 5.9) years, with 203 men at 42 years of age, 184 at 48 years of age, 167 at 54 years of age, and 58 at 60 years of age. Conditioning leisure-time physical activity averaged 119 (SD 98) hours per year, the mean BMI was 25.6 (SD 3.2) $\mathrm{kg} / \mathrm{m}^{2}$, alcohol consumption averaged 78 (SD 99) grams per week, and $25.5 \%$ were regular smokers. The distributions of all of the independent variables by IHD at baseline are listed in appendix A. Men with IHD were older, earned less, reported more mental strain at work, had higher levels of fibrinogen, and had lower values for blood pressure and cardiorespiratory fitness. As expected, the men with IHD spent less energy per potential standard workday than those without IHD. However, they were exposed to higher levels of energy expenditure at work than the men without IHD with respect to all of the other energy expenditure measures. Differences were also found for the men with and without carotid stenosis at baseline (data not shown).

\section{Progression of atherosclerosis}

The maxIMT at baseline averaged 0.91 (SD 0.21, range $0.54-2.62) \mathrm{mm}$. The average change in maxIMT was 0.027 (SD 0.017, range $-0.033-0.095$ ) $\mathrm{mm}$ per year, corresponding to a 0.33 (SD 0.24, range $-0.82-1.75$ ) $\mathrm{mm}$ change during the entire 11-year follow-up. This report focuses on the percentage of change in the maxIMT that averaged $2.72 \%$ per year and $29.9 \%$ (95\% CI $28.5 \%$ $31.4 \%$ ) for the entire 11.13-year follow-up.

\section{Energy expenditure at work}

Table 1 shows the distribution of the energy expenditure measures by age cohort and survey time. At baseline, the energy expenditure per typical workday ranged from 616 to $5418 \mathrm{kcal} /$ day with an average of $2046 \mathrm{kcal} /$ day. The average had changed little after 4 years $(2032 \mathrm{kcal} /$ day $)$ and had dropped slightly to $1916 \mathrm{kcal} / \mathrm{day}$ after 11 years. The measures of relative energy expenditure showed an increase with age that indicated that physical demands at work were relatively higher for the older workers than for the younger workers.

Table 2 shows the proportion of men by age group that exceeded the recommended maximum levels of $\% \mathrm{VO}_{2} \max$ [ie, $33 \%$ for work involving mostly lower extremities according to method $1(50,51,58)$ and $34 \%$ according to method 2]. At the baseline, 29.6 (method 1) to $31.2 \%$ (method 2) of all the men exceeded these levels, and there was a monotone increase in the proportion of men exposed to excessive levels of $\% \mathrm{VO}_{2} \max$ from about $20 \%$ of the men in the youngest age group up to $53 \%$ of the men in the oldest age group. The proportion of men experiencing excessive aerobic strain was higher (50-52\%) among those with IHD than among those without IHD (26-28\%).

By occupational group, the recommended (method 1) level was exceeded by $70 \%$ of the 71 men working in 
Table 1. Absolute and relative measures of energy expenditure by time of assessment and age cohort-Kuopio Ischemic Heart Disease Risk Factor Study 1984-2001 (N=612). Age refers to age cohort (ie, age at baseline regardless of the time of follow-up). $\left(\% \mathrm{VO}_{2} \mathrm{max}=\right.$ relateve aerobic strain, $\% \mathrm{VO}_{2} \mathrm{Res}=$ percent of oxygen uptake researve)

\begin{tabular}{|c|c|c|c|c|}
\hline Energy expenditure & N & Mean & SD & Range \\
\hline \multicolumn{5}{|l|}{ Absolute measures } \\
\hline \multicolumn{5}{|c|}{ Kilocalories per typical workday at baseline } \\
\hline Age 42 years & 203 & $2071 \mathrm{kcal}$ & 834 & $616-5066$ \\
\hline Age 48 years & 184 & 1983 kcal & 831 & $664-5418$ \\
\hline Age 54 years & 167 & 2109 kcal & 893 & $792-5292$ \\
\hline Age 60 years & 58 & $1974 \mathrm{kcal}$ & 799 & $684-4661$ \\
\hline Total & 612 & $2046 \mathrm{kcal}$ & 846 & $616-5418$ \\
\hline \multicolumn{5}{|c|}{ Kilocalories per typical workday at 4-year follow-up } \\
\hline Age 42 years & 191 & $2132 \mathrm{kcal}$ & 886 & $758-4809$ \\
\hline Age 48 years & 175 & 1942 kcal & 720 & $857-4172$ \\
\hline Age 54 years & 104 & $2045 \mathrm{kcal}$ & 946 & $439-4705$ \\
\hline Age 60 years & 20 & $1801 \mathrm{kcal}$ & 749 & $811-3571$ \\
\hline Total & 490 & 2032 kcal & 842 & $439-4809$ \\
\hline \multicolumn{5}{|c|}{ Kilocalories per typical workday at 11-year follow-up } \\
\hline Age 42 years & 166 & $1963 \mathrm{kcal}$ & 645 & $455-4152$ \\
\hline Age 48 years & 84 & 1825 kcal & 711 & $599-5232$ \\
\hline Age 54 years & 3 & $1915 \mathrm{kcal}$ & 1022 & $751-2664$ \\
\hline Age 60 years & - & . & & 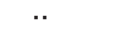 \\
\hline Total & 253 & $1916 \mathrm{kcal}$ & 672 & $455-5232$ \\
\hline
\end{tabular}

Total amount of kilocalories spent between the baseline and the 11-year follow-up (in $1000 \mathrm{kcal}$ )

$\begin{array}{lrlrr}\text { Age 42 years } & 204 & 4954 \mathrm{kcal} & 235 & 721-13507 \\ \text { Age 48 years } & 186 & 3940 \mathrm{kcal} & 2124 & 361-14586 \\ \text { Age } 54 \text { years } & 164 & 2830 \mathrm{kcal} & 2988 & 36-16469 \\ \text { Age 60 years } & 58 & 1608 \mathrm{kcal} & 1665 & 62-8933 \\ \text { Total } & 612 & 3759 \mathrm{kcal} & 2645 & 36-16469\end{array}$

Kilocalories per potential standard 8-hour workday between the baseline and the 11-year follow-up

\begin{tabular}{lrcrrr} 
Age 42 years & 204 & $1905 \mathrm{kcal}$ & 900 & $273-5209$ \\
Age 48 years & 186 & $1529 \mathrm{kcal}$ & 826 & $141-5691$ \\
Age 54 years & 164 & $1121 \mathrm{kcal}$ & 1173 & $15-6403$ \\
Age 60 years & 58 & $643 \mathrm{kcal}$ & 665 & $27-3638$ \\
Total & 612 & $1461 \mathrm{kcal}$ & 1023 & $15-6403$ \\
Relative measures & & & & & \\
\%VO ${ }_{2}$ max at baseline & & & & & \\
Age 42 years & 203 & $27.0 \%$ & 11.5 & $12.4-$ & 95.5 \\
Age 48 years & 184 & $27.1 \%$ & 10.2 & $12.5-$ & 63.6 \\
Age 54 years & 167 & $32.5 \%$ & 14.9 & $14.1-$ & 119.0 \\
Age 60 years & 58 & $34.1 \%$ & 10.1 & $13.1-$ & 56.2 \\
Total & 612 & $29.2 \%$ & 12.4 & $12.4-$ & 119.0 \\
\%V0 ${ }_{2}$ Res at baseline & & & & & \\
Age 42 years & 203 & $20.6 \%$ & 12.8 & $6.4-$ & 100.3 \\
Age 48 years & 184 & $20.3 \%$ & 11.4 & $5.8-$ & 61.8 \\
Age 54 years & 167 & $25.6 \%$ & 17.5 & $6.8-$ & 142.2 \\
Age 60 years & 58 & $25.9 \%$ & 11.2 & $6.7-$ & 52.4 \\
Total & 612 & $22.4 \%$ & 14.0 & $5.8-$ & 142.2 \\
\hline
\end{tabular}

agriculture, forestry, or commercial fishing, $44 \%$ of the 191 men working in manufacturing or construction, $26 \%$ of the 27 service workers, $25 \%$ of the 60 men in sales, $24 \%$ of the 58 men employed in transport or communication, $5 \%$ of the 55 men employed in administrative, managerial or clerical jobs, and 5\% of the 139 in technical, science or artistic work (data not shown).
Table 2. Proportion of men exceeding the recommended levels of relative aerobic strain at baseline by age cohort, baseline ischemic heart disease (IHD) status, and method to define maximum allowable levels.

\begin{tabular}{lccc}
\hline Age group & $\begin{array}{c}\text { All men } \\
(\%) \\
(\mathrm{N}=612)\end{array}$ & $\begin{array}{c}\text { Men without } \\
\text { IHD }(\%) \\
(\mathrm{N}=535)\end{array}$ & $\begin{array}{c}\text { Men with } \\
\text { IHD }(\%) \\
(\mathrm{N}=77)\end{array}$ \\
\hline Method $1^{\text {a }}$ & & & \\
Age 42 years & 19.7 & 18.7 & 40.0 \\
Age 48 years & 26.6 & 23.8 & 45.8 \\
Age 54 years & 36.5 & 33.1 & 51.6 \\
Age 60 years & 53.5 & 50.0 & 66.7 \\
Total & 29.6 & 26.5 & 50.7 \\
Method 2 & & & \\
Age 42 years & 21.7 & 20.7 & 40.0 \\
Age 48 years & 27.7 & 25.6 & 41.7 \\
Age 54 years & 38.9 & 34.6 & 58.0 \\
Age 60 years & 53.5 & 50.0 & 66.7 \\
Total & 31.2 & 28.2 & 52.0 \\
\hline
\end{tabular}

a Method 1: For men working less or more than 8 hours during a typical workday, relative aerobic strain was calculated as if they worked only 8 hours disregarding the extra energy expenditure and ignoring the fact that recommended levels for relative aerobic strain change with worktime (50). The threshold for excessive relative aerobic strain was set at 33\% for an 8-hour day on the basis of the literature $(50,58)$.

b Method 2: Thresholds for excessive aerobic strain calculated on the basis of a formula provided by Wu \& Wang (52), which gives the maximal allowable worktime (MAWT) based on relative aerobic strain $\left(\% 0_{2} \max \right):$ MAWT $=95.33 \mathrm{e}-7.28\left(\% \mathrm{VO}_{2} \max \right) \times 100$. The formula can be solved to yield maximum allowable relative aerobic strain $=(\ln (95.33)$ $\ln ($ worktime $)) \times 100 / 7.28$. For 8 hours of work this formula sets the maximum allowable level of aerobic strain at $34 \%$.

\section{Measures of association between energy expenditure and the progression of intima media thickness}

Table 3 shows that the RCR in the maxIMT during the 11-year follow-up was significantly associated with all of the energy expenditure measures. The effect measures varied little with incremental adjustment for covariates. Absolute measures of energy expenditure in kilocalories were associated with RCR values ranging from 1.13 to 1.18 in the fully adjusted model (last column of table 3 ). The adjusted relative energy expenditure measures showed the highest RCR values (RCR 1.23 and 1.24, respectively).

To check for thresholds and nonmonotone dose-response relationships, we explored models by using categorical exposure measures and also by entering quadratic terms of the exposure variables into the model. These models did not provide any evidence for thresholds and confirmed a positive monotone exponential association between all of the energy expenditure measures and the change in IMT.

\section{Energy expenditure and the percentage of change in intima media thickness}

Table 4 shows the percentage of change in IMT for all of the men during the 11-year follow-up at minimum, median, and maximum levels for each alternative measure 
Table 3. Relative change ratio a (RCR) for maximum intima media thickness (IMT) over the 11 -year follow-up with $95 \%$ confidence intervals $(95 \% \mathrm{CI})$, by measure of energy expenditure —results from the multiple regression analyses with incremental adjustment for the covariates (all men, $\mathrm{N}=612) .\left(\% \mathrm{VO}_{2} \mathrm{max}=\right.$ relative aerobic strain, $\% \mathrm{VO}_{2} \mathrm{Res}=$ percent of oxygen uptake reserve)

\begin{tabular}{|c|c|c|c|c|c|c|c|c|c|c|c|c|}
\hline \multirow[t]{2}{*}{ Energy expenditure } & \multicolumn{3}{|c|}{$\begin{array}{c}\text { Model } 1 \\
\text { (adjusted for } \\
\text { age and } \\
\text { technical factors) }\end{array}$} & \multicolumn{3}{|c|}{$\begin{array}{c}\text { Model } 2 \\
\text { (model } 1 \text { plus } \\
\text { adjustment for } \\
\text { biological factors) }\end{array}$} & \multicolumn{3}{|c|}{$\begin{array}{c}\text { Model } 3 \\
\text { (model } 2 \text { plus } \\
\text { adjustment for } \\
\text { behavioral factors) }\end{array}$} & \multicolumn{3}{|c|}{$\begin{array}{c}\text { Model } 4 \\
\text { (model } 3 \text { plus adjust- } \\
\text { ment for socioeconomic } \\
\text { status and psychosocial } \\
\text { job factors) }\end{array}$} \\
\hline & $\mathrm{RCR}$ & $95 \% \mathrm{Cl}$ & P-value & $\mathrm{RCR}$ & $95 \% \mathrm{Cl}$ & $\mathrm{P}$-value & $\mathrm{RCR}$ & $95 \% \mathrm{Cl}$ & P-value & e RCR & $95 \% \mathrm{Cl}$ & P-value \\
\hline \multicolumn{13}{|l|}{ Absolute measures } \\
\hline Kilocalories per typical w & 1.14 & $1.05-1.23$ & 0.001 & 1.12 & $1.03-1.21$ & 0.008 & 1.13 & $1.05-1.23$ & 0.002 & 1.13 & $1.04-1.23$ & 0.005 \\
\hline $\begin{array}{l}\text { Total number of kilocalories during the follow-up } \\
\text { Kilocalories per potential 8-hour standard workday }\end{array}$ & 1.17 & $1.07-1.29$ & 0.001 & 1.14 & $1.04-1.25$ & 0.005 & 1.18 & $1.07-1.30$ & 0.001 & 1.17 & $1.06-1.29$ & 0.001 \\
\hline during the follow-up & 1.19 & $1.09-1.31$ & 0.001 & 1.16 & $1.06-1.27$ & 0.002 & 1.19 & $1.09-1.31$ & 0.001 & 1.18 & $1.08-1.30$ & 0.001 \\
\hline \multicolumn{13}{|l|}{ Relative measures } \\
\hline $\begin{array}{l}\% \mathrm{VO}_{2} \text { max at baseline } \\
\% \mathrm{VO}_{2} \text { Res at baseline }\end{array}$ & $\begin{array}{l}1.20 \\
1.21\end{array}$ & $\begin{array}{l}1.06-1.35 \\
1.06-1.39\end{array}$ & 0.003 & $\begin{array}{l}1.18 \\
1.20\end{array}$ & $\begin{array}{l}1.04-1.33 \\
1.04-1.37\end{array}$ & $\begin{array}{l}0.010 \\
0.010\end{array}$ & $\begin{array}{l}1.24 \\
1.25\end{array}$ & $\begin{array}{l}1.07-1.43 \\
1.7-1.45\end{array}$ & $\begin{array}{l}0.004 \\
0.004\end{array}$ & $\begin{array}{l}1.23 \\
1.24\end{array}$ & $\begin{array}{l}1.06-1.44 \\
1.05-1.46\end{array}$ & 0.008 \\
\hline
\end{tabular}

a RCR per unit of change in IMT when the unit is the observed range (maximum-minimum) in the energy expenditure measure.

${ }^{\mathrm{b}}$ Adjusted for a total of 21 covariates, including the technical, biological, behavioral, socioeconomic, and psychosocial factors listed in appendix A.

Table 4. Percentage of change in maximum intima media thickness (IMT) and the relative change ratio ${ }^{\text {a }}$ (RCR) by the level of energy expenditure over the 11-year follow-up - results from the multiple regression analyses with adjustment for all 21 covariates $^{b}$ (All men, $\mathrm{N}=612)$. $\left(\% \mathrm{VO}_{2} \mathrm{max}=\right.$ relative aerobic strain, $\% \mathrm{VO}_{2} \mathrm{Res}=$ percent of oxygen uptake reserve)

\begin{tabular}{|c|c|c|c|c|c|c|c|c|c|}
\hline \multirow[t]{2}{*}{ Energy expenditure } & \multicolumn{2}{|c|}{ Minimum } & \multicolumn{2}{|c|}{ Median } & \multicolumn{2}{|c|}{ Maximum } & \multicolumn{2}{|c|}{$\mathrm{RCR}$} & \multirow[t]{2}{*}{ P-value } \\
\hline & $\%$ & $95 \% \mathrm{Cl}$ & $\%$ & $95 \% \mathrm{Cl}$ & $\%$ & $95 \% \mathrm{Cl}$ & $\%$ & $95 \% \mathrm{Cl}$ & \\
\hline \multicolumn{10}{|l|}{ Absolute measures } \\
\hline Kilocalories per typical workday at baseline & 27.6 & $22.7-32.6$ & 31.6 & $27.8-35.4$ & 44.3 & $35.1-54.1$ & 1.13 & $1.04-1.23$ & 0.005 \\
\hline $\begin{array}{l}\text { Total number of kilocalories during the follow-up } \\
\text { Kilocalories per potential 8-hour standard workday }\end{array}$ & 28.0 & $23.1-32.4$ & 31.7 & $28.0-35.5$ & 49.4 & $38.3-61.4$ & 1.17 & $1.06-1.29$ & 0.001 \\
\hline during the follow-up & 30.2 & $26.9-33.5$ & 34.9 & $32.9-36.9$ & 55.3 & $44.4-67.1$ & 1.18 & $1.08-1.30$ & 0.001 \\
\hline \multicolumn{10}{|l|}{ Relative measures } \\
\hline $\begin{array}{l}\% \mathrm{VO}_{2} \text { max at baseline } \\
\% \mathrm{VO}_{2} \text { Res at baseline }\end{array}$ & $\begin{array}{l}28.1 \\
29.0\end{array}$ & $\begin{array}{l}23.3-33.1 \\
24.5-33.6\end{array}$ & $\begin{array}{l}31.6 \\
31.6\end{array}$ & $\begin{array}{l}27.9-35.4 \\
27.9-35.4\end{array}$ & $\begin{array}{l}57.9 \\
60.0\end{array}$ & $\begin{array}{l}38.3-80.4 \\
38.4-85.0\end{array}$ & $\begin{array}{l}1.23 \\
1.24\end{array}$ & $\begin{array}{l}1.06-1.44 \\
1.05-1.46\end{array}$ & $\begin{array}{l}0.008 \\
0.010\end{array}$ \\
\hline
\end{tabular}

a RCR per unit of change in IMT when the unit is the observed range (maximum - minimum) in energy expenditure.

${ }^{b}$ Same covariates as in model 4 of table 3, including the 21 technical, biological, behavioral, socioeconomic, and psychosocial factors listed in appendix A.

of energy expenditure, together with the respective relative change ratios. The highest change was observed for the men at maximum $\% \mathrm{VO}_{2} \operatorname{Res}(60 \%, 95 \%$ confidence interval $38 \%-85 \%)$.

\section{Energy expenditure and the percentage of change in intima media thickness by baseline cardiovascular health status}

Table 5 shows the percentage of change in IMT separately for the men without and with preexisting IHD and their respective relative change ratios. Across all of the exposure measures, the men with IHD experienced consistently higher rates of IMT change than the men without IHD at baseline. Significant interactions $(\mathrm{P}<0.10)$ were found between IHD and the kilocalories per typical day at baseline, the $\% \mathrm{VO}_{2} \max$, and the $\% \mathrm{VO}_{2}$ Res. At a $\% \mathrm{VO}_{2}$ max of $119 \%$, the 11 -year change in IMT among the men with IHD (90\%) was nearly twice as high as among those without IHD (46\%). Figure 1 shows the same comparison for the minimum (6), mean (22, not median), and maximum (142) \% $\mathrm{VO}_{2} \mathrm{Res}$ values.

Table 6 shows the percentage of change for IMT and the RCR values separately for the men without and with preexisting carotid artery stenosis. Across all of the exposure measures, the men with carotid stenosis experienced consistently higher rates of IMT change than the men without preexisting stenosis. Significant interactions $(\mathrm{P}<0.20)$ were found between carotid stenosis and the total amount of energy expenditure and the kilocalories per potential 8-hour standard workday.

There was some overlap between the two cardiovascular health status subgroups in that $40.3 \%$ of the men with IHD also had stenosis of the carotid arteries and $24.4 \%$ of the men with carotid stenosis also had IHD. 
Table 5. Percentage of change in maximum intima media thickness (IMT) at the minimum, median, and maximum levels of energy expenditure, measures of association between energy expenditure and IMT progression [relative change ratio a (RCR)], and interactions between energy expenditure and baseline ischemic heart disease (IHD) status over the 11-year follow-up-results from the multiple regression analyses with adjustment for 21 covariates $^{b}(\mathrm{~N}=612)$. (Kcal per workday = kilocalories per typical workday at baseline, Total kcal during follow-up = total number of kilocalories during the follow-up, Kcal per potential workday = kilocalories per potential 8-hour standard workday during the follow-up, $\% \mathrm{VO}_{2} \mathrm{max}=$ relative aerobic strain at baseline, $\% \mathrm{VO}_{2}$ Res = percent of oxygen uptake reserve at baseline)

\begin{tabular}{|c|c|c|c|c|c|c|c|c|c|c|c|c|c|c|c|c|c|c|c|c|}
\hline \multirow{3}{*}{$\begin{array}{l}\text { Energy } \\
\text { expenditure }\end{array}$} & \multicolumn{9}{|c|}{ Men without IHD ( $N=535)$} & \multicolumn{9}{|c|}{ Men with IHD (N=77) } & \multirow{2}{*}{$\begin{array}{l}\text { Rate ratio } \\
\mathrm{RCR}_{\mathrm{HD}} / \\
\mathrm{RCR}_{\mathrm{NolHD}}\end{array}$} & \multirow{2}{*}{$\begin{array}{r}\begin{array}{l}\text { Inter- } \\
\text { action }\end{array} \\
\text { P-value }\end{array}$} \\
\hline & Min & mum & & dian & $\mathrm{Ma}$ & mum & & & P-value & Mini & num & & dian & $\operatorname{Max}$ & mum & & $\mathrm{CR}$ & P-value & & \\
\hline & $\%$ & $95 \% \mathrm{Cl}$ & $\%$ & $95 \% \mathrm{Cl}$ & $\%$ & $95 \% \mathrm{Cl}$ & $\%$ & $95 \% \mathrm{Cl}$ & & $\%$ & $95 \% \mathrm{Cl}$ & $\%$ & $95 \% \mathrm{Cl}$ & $\%$ & $95 \% \mathrm{Cl}$ & $\%$ & $95 \% \mathrm{Cl}$ & & $\% \quad 95 \% \mathrm{Cl}$ & \\
\hline
\end{tabular}

Absolute measures

Kcal/

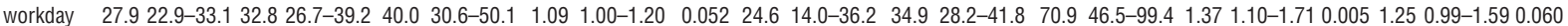
Total kcal

during

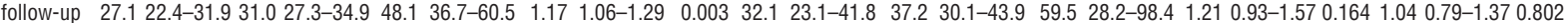
$\mathrm{Kcal} /$

potential

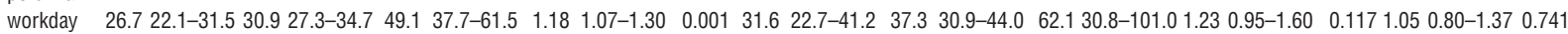
Relative measures

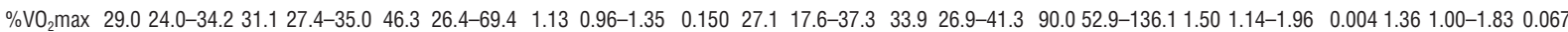

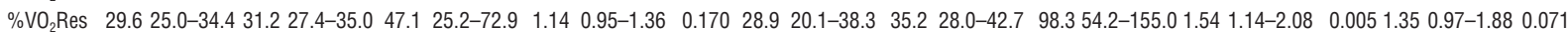

a RCR per unit of change in IMT when the unit is the observed range (maximum - minimum) in energy expenditure or \%V $\mathrm{O}_{2}$ max.

b Same covariates as in model 4 of table 3, including the 21 technical, biological, behavioral, socioeconomic, and psychosocial factors listed in appendix A.

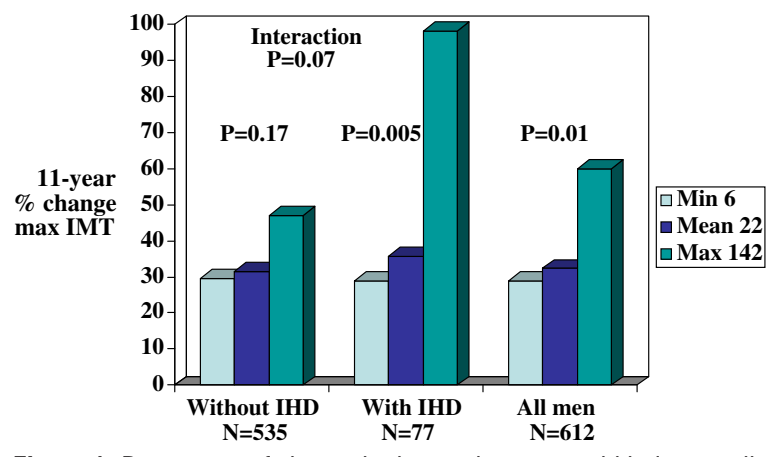

Figure 1. Percentage of change in the maximum carotid intima media thickness (IMT) over the 11-year follow-up at the minimum (6), mean (22), and maximum (142) percent of oxygen uptake reserve (\%VO $\left.{ }_{2} \mathrm{Res}\right)$, by ischemic heart disease (IHD) status at baseline and for all of the men. $(\min =$ minimum, $\max =$ maximum $)$

\section{Discussion}

\section{Progression of atherosclerosis}

During the entire 11-year follow-up, we observed an average change of 0.33 (SD 0.24, range -0.82-1.75) $\mathrm{mm}$ in the maximum IMT and 0.20 (SD 0.16, range $-0.55-1.25) \mathrm{mm}$ in the mean IMT. Changes of this magnitude are within the range reported in other studies (59). Such changes may be clinically significant because it has been shown in previous studies that cross-sectional differences of the order of $0.1 \mathrm{~mm}$ are associated with an $11 \%$ increase in the risk of acute myocardial infarction
$(60,61)$. While most of the participants experienced an increase in maxIMT over time, a minority of $4.25 \%$ experienced a decrease, pointing to the dynamic nature of the atherosclerotic disease process or inherent measurement error in assessing change.

\section{Observed levels of energy expenditure}

Counter to the widely held belief that most workers in industrialized countries lead a sedentary lifestyle devoid of aerobic strain, the study participants were physically rather active both during leisure and during work. On the average, these middle-aged Finnish men participated in 20 minutes of conditioning leisure-time physical activity per day (119 hours per year). At work, nearly one-third of all the participants exceeded the maximum level of $33 \% \mathrm{VO}_{2}$ max recommended for 8 hours of work (47, $50,51)$. It should be noted that this recommendation was based on prolonged dynamic work of large muscle groups used in walking or bicycling and that acceptable physical workloads are smaller for work involving the upper extremities or static work (62). The older men were exposed to much higher relative levels of energy expenditure than the younger men were; this finding indicates that the absolute caloric demands at work remained unchanged for these men even when their aerobic capacity decreased with age. In general, aerobic capacity declines by $1-2 \%$ per year after 25 years of age (63). Over $50 \%$ of the men with IHD exceeded the recommended maximum levels. The men working 
Table 6. Change in maximum intima media thickness (IMT) at the minimum, median, and maximum levels of energy expenditure, measures of association between energy expenditure and IMT progression [relative change ratio ${ }^{\text {a }}(\mathrm{RCR})$ ], and interactions between energy expenditure and the baseline status of carotid artery stenosis over the 11-year follow-up-results from the multiple regression analyses with adjustment for 21 covariates $^{b}(\mathrm{~N}=612)$. (Kcal per workday = kilocalories per typical workday at baseline, Total kcal during follow-up = total number of kilocalories during the follow-up, Kcal per potential workday = kilocalories per potential 8-hour standard workday during the follow-up, $\% \mathrm{VO}_{2} \max =$ relative aerobic strain at baseline, $\% \mathrm{VO}_{2} \mathrm{Res}=$ percent of oxygen uptake reserve at baseline)

\begin{tabular}{|c|c|c|c|c|c|c|c|c|c|c|c|c|c|c|c|c|c|c|c|}
\hline \multirow{3}{*}{$\begin{array}{l}\text { Energy ex- } \\
\text { penditure }\end{array}$} & \multicolumn{8}{|c|}{ Men without carotid stenosis ( $\mathrm{N}=485$ ) } & \multicolumn{9}{|c|}{ Men with carotid stenosis $(\mathrm{N}=127)$} & \multirow{2}{*}{$\begin{array}{l}\text { Rate ratio } \\
\mathrm{RCR}_{\text {Sten }} / \\
\mathrm{RCR}_{\text {NoSten }}\end{array}$} & \multirow{2}{*}{$\begin{array}{c}\begin{array}{l}\text { Inter- } \\
\text { action }\end{array} \\
\text { P-value }\end{array}$} \\
\hline & Minimum & & Median & & imum & & $C R$ & P-value & & nimum & & Median & & imum & & RCR & P-value & & \\
\hline & $\% \quad 95 \% \mathrm{Cl}$ & $\%$ & $95 \% \mathrm{Cl}$ & $\%$ & $95 \% \mathrm{Cl}$ & $\%$ & $95 \% \mathrm{Cl}$ & & $\%$ & $95 \% \mathrm{Cl}$ & $\%$ & $95 \% \mathrm{Cl}$ & $\%$ & $95 \% \mathrm{Cl}$ & $\%$ & $95 \% \mathrm{Cl}$ & & $\% \quad 95 \% \mathrm{Cl}$ & \\
\hline
\end{tabular}

Absolute measures

Kcal per

workday $27.922 .7-33.331 .127 .4-35.041 .3 \quad 31.3-52.1 \quad 1.11 \quad 1.00-1.22 \quad 0.045 \quad 29.120 .1-38.035 .329 .4-41.4 \quad 55.6 \quad 38.3-75.01 .201 .03-1.41 \quad 0.0221 .090 .91-1.310 .348$ Total kcal

during

follow-up 28.4 23.6-33.4 31.4 27.7-35.3 44.5 32.8-57.2 1.13 1.01-1.25 $0.027 \quad 28.9$ 21.6-36.6 36.4 30.5-42.6 $71.645 .8-101.91 .331 .10-1.62 \quad 0.0041 .18$ 0.95-1.47 0.124

Kcal per

potential

workday $27.823 .1-32.831 .227 .6-35.045 .7 \quad 34.0-58.4 \quad 1.14 \quad 0.97-1.21 \quad 0.01428 .821 .5-36.5 \quad 36.230 .4-42.4 \quad 70.4 \quad 45.2-99.81 .321 .09-1.60 \quad 0.0041 .160 .94-1.43 \quad 0.168$

Relative measures

$\% \mathrm{VO}_{2} \max 28.223 .2-33.531 .127 .4-35.052 .2 \quad 30.8-77.2 \quad 1.190 .99-1.42 \quad 0.058 \quad 30.422 .6-38.9 \quad 35.229 .2-41.5 \quad 71.641 .2-108.61 .321 .04-1.66 \quad 0.0221 .110 .85-1.46 \quad 0.440$

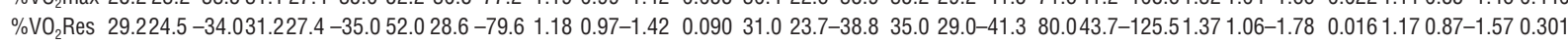

a RCR per unit of change in IMT when the unit is the observed range (maximum - minimum) in energy expenditure.

b Same covariates as in model 4 of table 3 including the 21 technical, biological, behavioral, socioeconomic, and psychosocial factors listed in appendix A.

in agriculture, forestry, fishery, manufacturing, or sales were the most often exposed to levels exceeding the recommendations. The average energy expenditure at work remained rather constant over time, this finding indicating that caloric work demands did not decline over an 11-year period for middle-aged men even as they transitioned into old age (data not shown). Another representative population study from the mid-1990s in Sweden found that $27 \%$ of working men and $22 \%$ of working women were required to do work that exceeded their aerobic capacity (64). These findings indicate that physically demanding work is still a prevalent feature among some occupational groups even in so-called modern service economies. Exposure is not limited to manufacturing, mining, or farming. In fact, many service workers perform their work standing or walking for many hours (eg, in sales, health care, or distribution). These upright work activities not only lead to high levels of energy expenditure, but also to additional cardiovascular strain due to venous pooling in the legs and resultant heart rate and blood pressure increases (20). For example, 62\% of the male employees in Quebec, Canada, perform their work in a predominantly standing posture (65). In emerging market economies with more agriculture and manufacturing jobs that already require larger amounts of physical labor, this problem is often compounded by unregulated work and recovery times that lead to regular workdays that may exceed 12-14 hours per day. Safe levels of energy expenditure under these circumstances are likely to be considerably lower than the maximum of $33-34 \% \mathrm{VO}_{2}$ max recommended for an 8-hour workday $(50,52)$, although more empirical work needs to be done to determine the safe levels of energy expenditure and work-rest patterns for long workshifts.

Misclassification of exposure may have occurred because the type and duration of the work activities were based on self-reported data rather than on direct observations and because the assessment of energy expenditure did not include upper-extremity work or the handling of external loads, but instead was limited to the energetic costs of moving one's own body or maintaining one's body posture (sitting, standing, walking, and climbing stairs). The amount of static work and the ambient temperature was also not accounted for, and the average MET values assigned to work activities may differ according to the individual body composition of fat and fat-free mass (66). Therefore, we believe that our estimates are conservative and underestimate the actual amount of energy expended at work. On the other hand, the nearly exclusive focus on lower-extremity activities in the computation of energy expenditure increases the validity of measures of relative energy expenditure based on the use of bicycle ergometer tests for the determination of maximum aerobic capacity $(67,62)$.

In addition, the use of a validated detailed occupational interview is an important methodological improvement over the methods used in most population-based 
studies of CVD that used limited exposure information from questionnaires typically yielding only broad exposure categories with lower power to detect any associations (3).

\section{Associations between energy expenditure and the progression of atherosclerosis}

Higher levels of energy expenditure at work were significantly associated with an increased progression of carotid atherosclerosis regardless of the type of exposure measure used and even after control for a total of 21 potential confounders, including several not controlled for in previous studies, such as leisure-time physical activity, psychosocial job factors, and fibrinogen, among others.

The observed increases in the rate of progression of atherosclerosis were consistently higher when better exposure measures were used, either utilizing a cumulative repeat-exposure measure alone, a cumulative repeat-exposure measure relative to the number of standard workdays, or baseline information relative to the individual workers' aerobic capacity. [See table 3.]

It is also noteworthy that adjustment for behavioral factors increased the risk estimates associated with occupational physical activity (model 3); this finding indicates negative confounding. Risk estimates remained at this level even after further adjustment for income, mental stress at work, stress from work deadlines, and social support from supervisors and co-workers (model 4). This finding indicates that the effects of energy expenditure are independent of socioeconomic status and psychosocial job factors that were associated with 4-year IMT progression in this study population as reported previously (26).

Our analyses indicate an exponential dose-response relationship between both absolute and relative measures of energy expenditure and the progression of atherosclerosis. On the basis of these findings, the hypothesis of a net protective effect of occupational physical activity (via a training effect) on the progression of atherosclerosis needs to be rejected. This result is in line with previous observations of work physiology and epidemiologic studies that physical workload does not have similar training effects on individual work capacity as aerobic physical exercise does $(68,69,51,70,71)$. Instead, our findings are consistent with the hypothesis of an atherogenic effect of occupational physical activity in which an increase in energy expenditure at work is associated with a progression of atherosclerosis.

\section{Interaction of energy expenditure with baseline cardio- vascular disease}

IHD at baseline showed strong interactions with energy expenditure. Similarly, preexisting carotid artery plaque or stenosis in combination with energy expenditure increased the progression of atherosclerosis. These results are consistent with the findings of an earlier 4-year prospective study in this population showing that prolonged standing at work (presumably leading to venous pooling and compensatory increases in heart rate) was found to be significantly associated with the progression of atherosclerosis and with effects significantly stronger among the men with preexisting IHD or carotid artery stenosis than among the healthy men (20).

These findings are consistent with the hemodynamic theory of atherosclerosis. Departing from the clinical fact (corroborated in this study) that men with IHD have a lower aerobic capacity, the hemodynamic theory predicts that men with IHD will respond to identical physical demands with higher elevations in heart rate than healthy men do, leading to increased intravascular turbulence and suboptimal wall shear stress, which has been implicated in the atherosclerotic disease process as earlier described and in detail elsewhere (34, 33, 35, 36, 20). Similarly, the hemodynamic theory predicts that arterial stenosis leads to increased poststenotic turbulences and suboptimal wall sheer stress as well. Elevated blood pressure, especially after static work, is another potential mechanism between occupational physical activity and the progression of atherosclerosis (72-74).

\section{Comparison with other studies and known risk factors}

We are aware of only one previous study that examined the relationship between occupational physical activity and IMT. The study found a significant positive association between occupational physical activity and IMT, however, only for blacks. This finding needs to be interpreted with caution because of the cross-sectional design, the use of crude measures of occupational physical activity based on occupational ratings, and failure to adjust for leisure-time physical activity (75).

While some beneficial effects of leisure-time physical activity on the circulatory system are relatively well established, the literature about the health effects of occupational physical activity remains inconsistent (5). Research in the 1950s and 1960s, comparing different occupational groups, identified sedentary work as an important cardiovascular risk factor (76-79). However, these earlier studies were vulnerable to alternative explanations because of selection bias and uncontrolled confounding. For example, in their pioneering work, Morris et al attributed the lower risk of coronary heart disease among London bus conductors versus drivers to the sedentary work of the drivers (79). Since then, research has shown that the excess risk in cardiovascular disease among urban bus drivers is not experienced by rural bus drivers, and, for urban bus drivers, is independent of both leisure-time physical activity and occupational 
physical activity $(80,81)$. Instead the excess risk is now thought to be attributable to the high levels of job stress experienced by urban bus drivers (82-85), a factor that may have confounded the reported association with sedentary work $(5,21)$. Clearly, the lack of control for psychosocial job factors in most previous studies of occupational physical activity is a major limitation of the literature. The current study overcomes this limitation by adjusting for several psychosocial job factors that were shown to be associated with the progression of atherosclerosis (26), myocardial infarction, and cardiovascular and all-cause mortality in this population (54). Similarly, in contrast to most other published studies, our study examined the independent effects of occupational physical activity by controlling for conditioning leisure-time physical activity in multivariate models.

Leisure-time physical activity did not predict the 11-year progression of atherosclerosis in any of our 20 regression models (P-values ranging from 0.21 to 0.84 ), confirming the results of an earlier 4-year prospective study of this cohort finding no significant associations of conditioning or nonconditioning leisure-time physical activity with a 4-year progression of atherosclerosis (37). However, energy expenditure of conditioning leisure-time physical activity showed a trend for an inverse association with a 4-year change in IMT (37). These findings deserve further inquiry because conditioning leisure-time physical activity, the measure used in our study, had been associated with a reduced risk of myocardial infarction in an earlier study of this population (45). One possible explanation for these paradoxical findings is the fact that typically only men with low levels of occupational physical activity engage in conditioning leisure-time physical activity outside of work so that occupational physical activity is inversely associated with leisure-time physical activity and may mask an inverse relationship of leisure-time physical activity with IMT. In fact, we observed a negative, albeit modest correlation between conditioning leisure-time physical activity and baseline energy expenditure at work (correlation $=-0.19$ ) or relative aerobic strain (correlation $=-0.22$ ) in our study population. Our findings therefore raise the question of whether previous reports on the benefits of leisure-time physical activity in studies not controlling for occupational physical activity could be due to uncontrolled confounding by occupational physical activity. It may be that the positive effects of leisure-time physical activity are confined to training effects of the cardiovascular system among people with little or no occupational physical activity. A recent case-control study of myocardial infarction supports this hypothesis (22). Training effects can be achieved with a short duration of leisure-time physical activity of less than 30 minutes per day and can be expected to lead to a net reduction in average heart rate during other daily activities and during rest, a beneficial effect according to the hemodynamic theory of atherosclerosis (33). None of these beneficial training effects would be expected in people who are already engaged in physically demanding work, and there is some empirical evidence for an interaction between leisure-time physical activity and occupational physical activity (86). This finding corresponds to the observation that depressed endothelial function and shear stress regulation in people with CVD is more amenable to improvement through exercise training than normal endothelial function is in the young and healthy (87). Since recommended levels of leisuretime physical activity are a full magnitude smaller than typical levels of occupational physical activity, one would also not expect a substantially increased health risk due to conditioning leisure-time physical activity among men performing physically demanding work; in fact increases in leisure-time physical activity were not associated with IMT change in our study $(\mathrm{P}=0.745$, see appendix B).

Although our observed negative correlation between leisure-time physical activity and occupational physical activity is in line with observations made by the Surgeon General's report that blue-collar workers' participation in leisure-time physical activity is relatively low, we would question the report's promise of an agenda that states as its only goal to increase leisure-time physical activity among blue-collar workers $(3,88)$. For some workers, targeted worksite exercise programs may be beneficial for increasing fitness or reducing weight (88). However, among the nearly $30 \%$ of workers already exceeding safe limits for energy expenditure at work, additional aerobic exercise outside work may cause more fatigue and overexertion injuries of the musculoskeletal system without any proved benefits for the cardiovascular system. Instead, these workers may be in need of nonaerobic activities such as nonstrenuous stretching exercises to maintain flexibility and more recovery time between work periods to allow their heart rates and blood pressure to fall to sustainable levels (89). Ergonomic interventions that change work methods may help to reduce aerobic strain in specific occupations (90). Therefore, instead of trying to increase leisure-time physical activity indiscriminately among blue-collar workers, intervention research should be directed to (i) develop feasible screening programs to identify workers at risk, (ii) identify ways of lowering the physical demands for workers who still expend unsustainable amounts of energy at work, (iii) determine safe work-rest schedules, and (iv) guide regulators and stakeholders in the creation of workplaces promoting both cardiovascular and musculoskeletal health. In addition, it seems necessary to (v) empirically determine safe levels of energy expenditure for workdays exceeding 8 hours (91) and to (vi) find ways to provide aging 
workers and workers who have preexisting IHD or stenosis of carotid (or other) arteries with jobs that do not expose them to an increased risk of progression of their atherosclerotic disease. Research is also needed to (vii) determine the proportion and costs of CVD that are attributable to excessive levels of occupational physical activity and could be prevented through job redesign. Such data will be helpful in allocating the necessary resources to this field of research and respective worksite health promotion and disease prevention programs.

With regard to other known cardiovascular risk factors, our study confirms age, elevated LDL cholesterol, systolic blood pressure, and heavy smoking as independent risk factors for the progression of atherosclerosis, but failed to show an independent association with leisure-time physical activity, BMI, blood glucose, HDL cholesterol, personal income, or psychosocial job factors. [See regression coefficients in appendix B.] Several studies have linked exposure to specific physical and psychosocial job factors with cardiovascular disease and mortality $(92,23-25,27)$ but, similar to studies on occupational physical activity, findings have also been both positive and negative $(23,93-95)$ and typically did not adjust for occupational physical activity and leisuretime physical activity. Further investigations are needed to disentangle the interdependent relationships between occupational physical activity, leisure-time physical activity, and other factors as predictors of the progression of atherosclerosis and CVD. It should be noted that our method of adjusting for all these covariates together in one model might have led to overadjustment with respect to some covariates because they may represent intermediate pathway variables between, for example, socioeconomic status and CVD.

The findings of this study await confirmation in comparable prospective studies of IMT in other populations. It is also necessary to investigate further the associations between occupational physical activity and manifest CVD or mortality. However, studies of symptomatic chronic disease outcomes often fail to detect associations with work exposures because of disease-based selection out of strenuous jobs by those affected. The study of preclinical outcomes such as IMT changes is less likely to be influenced by these selection effects and therefore may be more important in the determination of causal relationships and appropriate interventions.

\section{Implications for prevention and medical practice}

The findings of this study may have important implications for the practice of occupational and rehabilitative medicine. Primary CVD prevention efforts may benefit from a reduction in the caloric demands of physically demanding jobs. Jobs in agriculture, forestry, commercial fishing, manufacturing, or sales are at especially high risk of leading to excessive aerobic strain. Secondary and tertiary prevention efforts may be indicated for persons who do not have a sitting desk job. Specifically, $\% \mathrm{VO}_{2} \max$ or $\% \mathrm{VO}_{2}$ Res should be routinely assessed in such workplaces during the placement of new employees, and in the process of designing work modifications for employees returning to work after being diagnosed with IHD. Both bicycle ergometry and ambulatory electrocardiography may be warranted for workers with CVD (96). Indirect assessments of relative energy expenditure based solely on heart rate (HR) measurements at work have become feasible through commercially available portable heart rate monitoring equipment and may be sufficient for assessments of workers without CVD.

Because it has been shown that $\% \mathrm{VO}_{2}$ Res is highly correlated with the percentage of heart rate reserve $[\% \mathrm{HRR}=(\mathrm{HR}$ work $-\mathrm{HR}$ rest $) /(\mathrm{HRmax}-$ HRrest $) \times 100 \%$ ] across the aerobic fitness spectrum $(67,48)$, it is possible to estimate the percentage of heart rate reserve (\%HRR) (67), HR-estimated energy expenditure (HREEE), and $\% \mathrm{VO}_{2}$ Res using recently validated procedures (97) in combination with standard procedures estimating maximum heart rate based on resting heart rate and age (98) without the necessity of employing laboratory-based gas exchange analyses or bicycle ergometer tests.

It is best to use these relative measures of energy expenditure because they take individual differences in $\mathrm{VO}_{2}$ max into account. $\mathrm{VO}_{2} \max$ has been found to differ markedly by gender, age, health status, and other factors (63). Relative measures correlate better with fatigue, heart rate elevations, and related health consequences of aerobic strain at work than absolute measures as shown by others (99), and, for the first time, for atherosclerosis in this study.

\section{Concluding remarks}

In conclusion, this study demonstrates for the first time that high energy expenditure at work is associated with an accelerated progression of carotid atherosclerosis even after control for virtually all known cardiovascular risk factors, including leisure-time physical activity, aerobic fitness, socioeconomic status, and psychosocial job factors that have been rarely controlled simultaneously. Older workers, workers with preexisting IHD, and workers with carotid stenosis appear to be especially vulnerable to the atherogenic effects of increasing levels of energy expenditure. The findings are consistent with the hemodynamic theory of atherosclerosis.

The results of this study do not support the notion that heavy physical labor has ceased to be a potential health hazard in the so-called modern service economy. To the contrary, they show that a substantial proportion 
of aging men and over $50 \%$ of those with IHD in this sample were still exposed to excessive caloric job demands according to current recommended maximum levels for $\% \mathrm{VO}_{2} \max$.

Job evaluations using ambulatory heart rate monitoring to estimate $\% \mathrm{VO}_{2} \max$ or $\% \mathrm{VO}_{2} \mathrm{Res}$ should be considered for every job requiring physical effort other than mostly sitting at a desk and for the evaluation of work modifications for workers with CVD.

Regulatory statutes dealing with worktime and rest schedules need to assure that workers are protected from excessive aerobic strain even if individual monitoring is not available. Such prevention measures are especially needed for older workers with age- or disease-related reduced cardiorespiratory fitness, existing IHD, or known atherosclerosis.

\section{Acknowledgments}

This work was funded by grant R01 OH007820, awarded by the National Institute for Occupational Safety and Health (NIOSH), Centers for Disease Control and Prevention (CDC), United States Department of Health and Human Services (DHHS).

The authors would like to express their gratitude to Dr Kimmo Ronkainen of the School of Public Health, University of Kuopio, for managing and updating the source data.

\section{References}

1. Powell KE, Thompson PD, Caspersen CJ, Kendrick JS. Physical activity and the incidence of coronary heart disease. Annu Rev Public Health. 1987;8:253-87.

2. Berlin JA, Colditz GA. A meta-analysis of physical activity in the prevention of coronary heart disease. Am J Epidemiol. 1990;132(4):612-28.

3. US Department of Health and Human Services. Physical activity and health: a report of the Surgeon General. Atlanta (GA): US Department of Health and Human Services, Centers for Disease Control and Prevention, National Center for Chronic Disease Prevention and Health Promotion; 1996. p 259.

4. Lee IM, Paffenbarger RS Jr, Hennekens CH. Physical activity, physical fitness and longevity. Aging Clin Exp Res. 1997;9(12):2-11.

5. Kristal-Boneh E, Silber H. Notes on the health effects of leisure time versus work related physical activity. Israel J Occup Health. 1998;2:179-84.

6. Salonen JT, Puska P, Tuomilehto J. Physical activity and risk of myocardial infarction, cerebral stroke and death: a longitudinal study in Eastern Finland. Am J Epidemiol. 1982;115(4):52637.

7. Menotti A, Seccareccia F. Physical activity at work and job responsibility as risk factors for fatal coronary heart disease and other causes of death. J Epidemiol Community Health. 1985;39(4):325-9.

8. Lapidus L, Bengtsson C. Socioeconomic factors and physical activity in relation to cardiovascular disease and death: a 12 year follow up of participants in a population study of women in Gothenburg, Sweden. Br Heart J. 1986;55(3):295-301.

9. Salonen JT, Slater JS, Tuomilehto J, Rauramaa R. Leisure time and occupational physical activity: risk of death from ischemic heart disease. Am J Epidemiol. 1988;127(1):87-94.

10. Seccareccia F, Menotti A. Physical activity, physical fitness and mortality in a sample of middle aged men followed-up 25 years. J Sports Med Phys Fitness. 1992;32(2):206-13.

11. Hu G, Jousilahti P, Borodulin K, Barengo NC, Lakka TA, Nissinen A, et al. Occupational, commuting and leisure-time physical activity in relation to coronary heart disease among middle-aged Finnish men and women. Atherosclerosis. 2006.

12. Kannel WB, Belanger A, D’Agostino R, Israel I. Physical activity and physical demand on the job and risk of cardiovascular disease and death: the Framingham Study. Am Heart J. 1986;112(4):820-5.

13. Sobolski J, Kornitzer M, De Backer G, Dramaix M, Abramowicz M, Degre S, et al. Protection against ischemic heart disease in the Belgian Physical Fitness Study: physical fitness rather than physical activity? Am J Epidemiol. 1987;125(4):601-10.

14. Johansson S, Rosengren A, Tsipogianni A, Ulvenstam G, Wiklund I, Wilhelmsen L. Physical inactivity as a risk factor for primary and secondary coronary events in Goteborg, Sweden. Eur Heart J. 1988;9 suppl L:8-19.

15. Harmsen $P$, Rosengren A, Tsipogianni A, Wilhelmsen L. Risk factors for stroke in middle-aged men in Goteborg, Sweden. Stroke. 1990;21(2):223-9.

16. Menotti A, Keys A, Blackburn H, Aravanis C, Dontas A, Fidanza F, et al. Twenty-year stroke mortality and prediction in twelve cohorts of the Seven Countries Study. Int J Epidemiol. 1990;19(2):309-15.

17. Haapanen N, Miilunpalo S, Vuori I, Oja P, Pasanen M. Characteristics of leisure time physical activity associated with decreased risk of premature all-cause and cardiovascular disease mortality in middle-aged men. Am J Epidemiol. 1996;143(9):870-80.

18. Stender M, Hense HW, Doring A, Keil U. Physical activity at work and cardiovascular disease risk: results from the MONICA Augsburg study. Int J Epidemiol. 1993;22(4):644-50.

19. Eaton CB, Medalie JH, Flocke SA, Zyzanski SJ, Yaari S, Goldbourt U. Self-reported physical activity predicts long-term coronary heart disease and all-cause mortalities: twenty-oneyear follow-up of the Israeli Ischemic Heart Disease Study. Arch Fam Med. 1995;4(4):323-9.

20. Krause N, Lynch JW, Kaplan GA, Cohen RD, Salonen R, Salonen JT. Standing at work and progression of carotid atherosclerosis. Scand J Work Environ Health. 2000;26(3):227-36.

21. Kristal-Boneh E, Harari G, Melamed S, Froom P. Association of physical activity at work with mortality in Israeli industrial employees: the CORDIS study. J Occup Environ Med. 2000;42(2):127-35.

22. Lopes C, Santos AC, Azevedo A, Maciel MJ, Barros H. Physical activity and risk of myocardial infarction after the fourth decade of life. Rev Port Cardiol. 2005;24(10):1191-207.

23. Kristensen TS. Cardiovascular diseases and the work environment: a critical review of the epidemiologic literature on nonchemical factors [review]. Scand J Work Environ Health. 1989;15:165-79.

24. Theorell T. The psycho-social environment, stress, and coronary heart disease. In: Marmot M, Elliott P, editors. Coronary 
heart disease epidemiology: from aetiology to public health. New York (NY): Oxford University Press, 1992:256-73.

25. Schnall P, Landsbergis P, Baker D. Job strain and cardiovascular disease. Ann Rev Public Health. 1994;15:381-411.

26. Lynch JW, Krause N, Kaplan GA, Cohen R, Salonen R, Salonen JT. Workplace demands, economic reward, and the progression of carotid atherosclerosis. Circulation. 1997;96(1):320-7.

27. Schnall PL, Belkic K, Landsbergis P, Baker D. The workplace and cardiovascular disease. Philadelphia (PA): Hanley \& Belfus; 2000. State of the Art Reviews in Occupational Medicine 334.

28. Crouse J, Thompson C. An evaluation of methods for imaging and quantifying coronary and carotid lumen stenosis and atherosclerosis. Circulation. 1993;87 suppl II:17-33.

29. Salonen JT, Salonen R. Ultrasound B-mode imaging in observational studies of atherosclerotic progression. Circulation. 1993;87(3 suppl):II-56-II-65.

30. Young W, Gofman J, Tandy R, Malamud N, Waters E. The quantitation of atherosclerosis, III: the extent of correlation of degrees of atherosclerosis within and between the coronary artery and cerbral vascular beds. Am J Cardiol. 1960;6:300-8.

31. Salonen JT, Korpela H, Salonen R, Nyssönen K. Precision and reproducibility of ultrasonographic measurement of progression of common carotid artery atherosclerosis. Lancet. 1993;341:1158-9.

32. Touboul PJ, Hennerici MG, Meairs S, Adams H, Amarenco P, Bornstein N, et al. Mannheim carotid intima-media thickness consensus (2004-2006): an update on behalf of the Advisory Board of the 3rd and 4th Watching the Risk Symposium, 13th and 15th European Stroke Conferences, Mannheim, Germany, 2004, and Brussels, Belgium, 2006. Cerebrovasc Dis. 2007;23(1):75-80.

33. Glagov S, Giddens D, Ku D. Hemodynamics and atherosclerosis: insights and perspectives gained from studies of human arteries. Arch Pathol Lab Med. 1988;112:1018-31.

34. Ku DN, Giddens DP, Zarins CK, Glagov S. Pulsatile flow and atherosclerosis in the human carotid bifurcation: positive correlation between plaque location and low oscillating shear stress. Arteriosclerosis. 1985;5(3):293-302.

35. Gotlieb AI, Langille BL. The role of rheology in atherosclerotic coronary artery disease. In: Fuster V, Ross R, Topol EJ, editors. Atherosclerosis and coronary artery disease. Philadelphia (PA): Lippincott-Raven Publishers; 1996. p 595-606.

36. Schoen FJ, Cotran RS. Blood vessels. In: Cotran RS, Kumar V, Collins T, Robbins SL, editors. Pathologic basis of disease. Philadelphia (PA): WB Saunders Company; 1999.

37. Lakka TA, Laukkanen JA, Rauramaa R, Salonen R, Lakka HM, Kaplan GA, et al. Cardiorespiratory fitness and the progression of carotid atherosclerosis in middle-aged men. Ann Intern Med. 2001;134:12-20.

38. Salonen JT. Is there a continuing need for longitudinal epidemiologic research? The Kuopio Ischaemic Heart Disease Risk Factor Study. Ann Clin Res. 1988;20(1-2):46-50.

39. Espeland MA, Craven TE, Riley WA, Corson J, Romont A, Furberg CD. Reliability of longitudinal ultrasonographic measurements of carotid intimal-medial thicknesses. Stroke. 1996;27(3):480-5.

40. Tang R, Hennig M, Thomasson B, Scherz R, Ravinetto R, Catalini R, et al. Baseline reproducibility of B-mode ultrasonic measurement of carotid artery intima-media thickness: the European Lacidipine Study on Atherosclerosis (ELSA). J Hypertens. 2000;18(2):197-201.

41. Lakka TA, Salonen JT. Intra-person variability of various physical activity assessments in the Kuopio Ischaemic Heart
Disease Risk Factor Study. Int J Epidemiol. 1992;21(3):46772.

42. Manninen P, Heliövaara M, Riihimäki H, Suomalainen O Physical workload and the risk of severe knee osteoarthritis. Scand J Work Environ Health. 2002;28(1):25-32.

43. Salonen JT, Lakka TA. Assessment of physical activity in population studies-validity and consistency of the methods in the Kuopio ischemic heart disease risk factor study. Scand J Sports Sci. 1987;9(3):89-95.

44. Ainsworth BE, Haskell WL, Leon AS, Jacobs DR Jr, Montoye HJ, Sallis JF, et al. Compendium of physical activities: classification of energy costs of human physical activities. Med Sci Sports Exerc. 1993;25(1):71-80.

45. Lakka T, Venäläinen JM, Rauramaa R, Salonen R, Tuomilehto J, Salonen JT. Relation of leisure-time physical activity and cardiorespiratory fitness to the risk of acute myocardial infarction. N Engl J Med. 1994;330:1549-1554.

46. Karpansalo M, Lakka T, Manninen P, Kauhanen J, Rauramaa R, Salonen JT. Cardiorespiratory fitness and risk of disability pension: a prospective population-based study in Finnish men. Occup Environ Med. 2003;60:765-769.

47. Jorgensen K. Permissible loads based on energy expenditure measurements. Ergonomics. 1985;28(1):365-9.

48. Howley ET. Type of activity: resistance, aerobic and leisure versus occupational physical activity. Med Sci Sports Exerc. 2001;33(6 suppl):S364-9; discussion S419-20.

49. Astrand P-O, Rodahl K. Textbook of work physiology, physiological bases of exercise. New York (NY): McGraw-Hill Book Company; 1986. p 756.

50. Rodgers SH, Kenworth DA, Eggleton EM. Ergonomic design for people at work. New York (NY): Van Nostrand Reinhold; 1986.

51. Ilmarinen J. Job design for the aged with regard to decline in their maximal aerobic capacity, part II-the scientific basis for the guide. Int J Ind Ergon. 1992;10:65-77.

52. Wu HC, Wang MJ. Relationship between maximum acceptable work time and physical workload. Ergonomics. 2002;45(4):280-9.

53. Lynch JW, Kaplan GA, Cohen RD, Tuomilehto J, Salonen JT. Do cardiovascular risk factors explain the relation between socioeconomic status, risk of all-cause mortality, cardiovascular mortality, and acute myocardial infarction? Am J Epidemiol. 1996;144(10):934-42.

54. Lynch J, Krause N, Kaplan GA, Tuomilehto J, Salonen JT. Workplace conditions, socioeconomic status, and the risk of mortality and acute myocardial infarction: the Kuopio Ischemic Heart Disease Risk Factor Study. Am J Public Health. 1997;87(4):617-22.

55. Kauhanen J, Kaplan GA, Goldberg DE, Salonen R, Salonen JT. Pattern of alcohol drinking and progression of atherosclerosis. Arterioscler Thromb Vasc Biol. 1999;19(12):3001-6.

56. Taylor HL, Jacobs DRJ, Schucker B, Knudsen J, Leon AS, Debacker G. A questionnaire for the assessment of leisure time physical activities. J Chronic Dis. 1978;31(12):741-55.

57. Rose GA, Blackburn H, Gillum RF. Cardiovascular survey methods. Geneva: World Health Organization; 1982.

58. Ilmarinen J. Job design for the aged with regard to decline in their maximal aerobic capacity, part I-guidelines for the practitioner. Int J Ind Ergon. 1992;10:53-63.

59. Bots ML, Evans GW, Riley WA, Grobbee DE. Carotid intimamedia thickness measurements in intervention studies: design options, progression rates, and sample size considerations: a point of view. Stroke. 2003;34(12):2985-94.

60. Salonen JT, Salonen R. Ultrasonographically assessed carotid 
morphology and the risk of coronary heart disease. Atheroscler Thromb. 1991;11:1245-9.

61. Chambless LE, Heiss G, Folsom AR, Rosamund W, Szklo M, Sharett AR, et al. Association of coronary heart disease incidence with carotid wall thickness and major risk factors: The Atherosclerosis Risk in Communities (ARIC) Study. Am J Epidemiol. 1997;146:483-94.

62. Aminoff T, Smolander J, Korhonen O, Louhevaara V. Prediction of acceptable physical work loads based on responses to prolonged arm and leg exercise. Ergonomics. 1998;41(1):109_ 20.

63. Shvartz E, Reibold RC. Aerobic fitness norms for males and females aged 6 to 75 years: a review. Aviat Space Environ Med. 1990;61(1):3-11.

64. Karlqvist L, Leijon O, Harenstam A. Physical demands in working life and individual physical capacity. Eur J Appl Physiol. 2003;89(6):536-47.

65. Tissot F, Messing K, Stock S. Standing, sitting and associated working conditions in the Quebec population in 1998. Ergonomics. 2005;48(3):249-69.

66. Byrne NM, Hills AP, Hunter GR, Weinsier RL, Schutz Y. Metabolic equivalent: one size does not fit all. J Appl Physiol. 2005;99(3):1112-9.

67. Swain DP, Leutholtz BC. Heart rate reserve is equivalent to $\% \mathrm{VO} 2$ reserve, not to \%VO2max. Med Sci Sports Exerc. 1997;29(3):410-4

68. Ilmarinen J, Louhevaara V, Korhonen O, Nygård CH, Hakola T, Suvanto S. Changes in maximal cardiorespiratory capacity among aging municipal employees. Scand J Work Environ Health. 1991;17 suppl 1:99-109.

69. Nygård $\mathrm{CH}$, Eskelinen L, Suvanto S, Tuomi K, Ilmarinen J. Associations between functional capacity and work ability among elderly municipal employees. Scand J Work Environ Health. 1991;17 suppl 1:122-7.

70. Torgen M, Punnett L, Alfredsson L, Kilbom A. Physical capacity inrelation to present and past physical load at work: a study of 484 men and women aged 41 to 58 years. Am J Ind Med. 1999;36:388-400.

71. Schibye B, Hansen AF, Sogaard K, Christensen H. Aerobic power and muscle strength among young and elderly workers with and without physically demanding work tasks. Appl Ergon. 2001;32(5):425-31.

72. Hanson P, Nagle F. Isometric exercise: cardiovascular responses in normal and cardiac populations. Cardiol Clin. 1987;5(2):157-70.

73. Schwartz J, Warren K, Pickering TG. Mood, location and physical position as predictors of ambulatory blood pressure and heart rate: application of a multi-level random effects model. Ann of Behav Med. 1994;16(3):210-20.

74. Dasinger LK, Krause N, Brand RJ, Kaplan GA, Salonen JT. Percent time at work in an upright posture associated with 11year change in systolic blood pressure. 4th International Conference on Work Environment and Cardiovascular Diseases. Newport Beach, California, March 9-11, 2005.

75. Muntaner C, Nieto FJ, Cooper L, Meyer J, Szklo M, Tyroler HA. Work organization and atherosclerosis: findings from the ARIC study. Atherosclerosis Risk in Communities. Am J Prev Med. 1998;14(1):9-18.

76. Morris JN, Heady JA, Raffle PAB, Roberts CG, Parks JW. Coronary heart disease and physical activity of work (Part 1). Lancet. 1953;2:1111-20.

77. Morris JN, Crawford MD. Coronary heart disease and physical activity of work: evidence of a national necropsy. Br Med J. 1958;2:1485-96.
78. Taylor HL, Klepetar E, Keys A, Parlin W, Blackburn H, Puchner T. Death rates among physically active and sedentary employees of the railroad industry. Am J Public Health. 1962;52:1697-1707.

79. Morris JN, Kagan A, Pattison DC, Gardner MJ. Incidence and prediction of ischaemic heart-disease in London busmen. Lancet. 1966;2(7463):553-9.

80. Rosengren A, Anderson K, Wilhelmsen L. Risk of coronary heart disease in middle-aged male bus and tram drivers compared to men in other occupations: a prospective study. Int J Epidemiol. 1991;20(1):82-7.

81. Gustavsson P, Alfredsson L, Brunnberg H, Hammar N, Jakobsson R, Reuterwall C, et al. Myocardial infarction among male bus, taxi, and lorry drivers in middle Sweden. Occup Environ Med. 1996;53(4):235-40.

82. Hartvig P, Midttun O. Coronary heart disease risk factors in bus and truck drivers. A controlled cohort study. Int Arch Occup Environ Health. 1983;52(4):353-60.

83. Belki\{c K, Savi\{c C, Theorell T, Raki\{c L, Ercegovac D, Djordjevi\{c M. Mechanisms of cardiac risk among professional drivers [review]. Scand J Work Environ Health. 1994;20(2):73-86.

84. Evans GW. Working on the hot seat: Urban bus operators. Accid Anal Prev. 1994;26(2):181-93.

85. Tüchsen F, Endahl LA. Increasing inequality in ischaemic heart disease morbidity among employed men in Denmark 1981-1993: the need for a new preventive policy. Int J Epidemiol. 1999;28(4):640-4.

86. Hu G, Eriksson J, Barengo NC, Lakka TA, Valle TT, Nissinen A, et al. Occupational, commuting, and leisure-time physical activity in relation to total and cardiovascular mortality among Finnish subjects with type 2 diabetes. Circulation. 2004;110(6):666-73.

87. Green DJ, Maiorana A, O'Driscoll G, Taylor R. Effect of exercise training on endothelium-derived nitric oxide function in humans. J Physiol. 2004;561(Pt 1):1-25.

88. King AC, Carl F, Birkel L, Haskell WL. Increasing exercise among blue-collar employees: the tailoring of worksite programs to meet specific needs. Prev Med. 1988;17(3):357-65.

89. Patterson RP, Pearson J, Fisher SV. Work-rest periods: their effects on normal physiologic response to isometric and dynamic work. Arch Phys Med Rehabil. 1985;66(6):348-52.

90. Hopsu L, Louhevaara V. Effects of the developmental work research on the aging cleaners - a pilot study. In: Ilmarinen J, editor. Proceedings of the International Scientific Symposium of Aging and Work. Helsinki: Finnish Institute of Occupational Health and International Conference on Occupational Health, May 28-30, 1992:166-9.

91. Tüchsen F. Working hours and ischaemic heart disease in Danish men: a 4-year cohort study of hospitalization. Int J Epidemiol. 1993;22(2):215-21.

92. Kristensen TS. Cardiovascular diseases and the work environment: a critical review of the epidemiologic literature on chemical factors [review]. Scand J Work Environ Health. 1989;15(4):245-64.

93. Suadicani P, Hein HO, Gyntelberg F. Are social inequalities as associated with the risk of ischemic heart disease a result of psychosocial working conditions? Atherosclerosis. 1993;101(2):165-75

94. Alterman T, Shekelle R, Vernon S, Bur K. Decision latitude, psychologic demand, job strain, and coronary heart disease in the Western Electric Study. Am J Epidemiol. 1994;139(6):620 7.

95. Hlatky M, Lam L, Lee K, Clapp-Channing N, Williams R, 
Pryor D, et al. Job strain and the prevalence and outcome of coronary artery disease. Circulation. 1995;92(3):327-33.

96. Haskell WL, Brachfeld N, Bruce RA, Davis PO, Dennis CA, Fox SM 3rd, et al. Task Force II: Determination of occupational working capacity in patients with ischemic heart disease. J Am Coll Cardiol. 1989;14(4):1025-34.

97. Garet M, Boudet G, Montaurier C, Vermorel M, Coudert J, Chamoux A. Estimating relative physical workload using heart rate monitoring: a validation by whole-body indirect calorim- etry. Eur J Appl Physiol. 2005;94(1-2):46-53.

98. Karvonen MJ, Kentala E, Mustala O. The effects of training on heart rate; a longitudinal study. Ann Med Exp Biol Fenn. 1957;35(3):307-15.

99. Wu HC, Wang MJ. Determining the maximum acceptable work duration for high-intensity work. Eur J Appl Physiol. 2001;85(3-4):339-44.

Received for publication: 2 November 2006 


\section{Appendix A}

Characteristics of the study population and the distribution of the independent variables by IHD (ischemic heart disease) status at baseline $(\mathrm{N}=612)\left(\mathrm{FIM}=\right.$ Finnish marks, $\% \mathrm{VO}_{2} \max =$ relative aerobic strain, $\% \mathrm{VO}_{2} \mathrm{Res}=$ percent of oxygen uptake reserve)

\begin{tabular}{|c|c|c|c|c|c|c|c|c|c|}
\hline \multirow[t]{2}{*}{ Independent variables } & \multicolumn{4}{|c|}{ Men without IHD (N=535) } & \multicolumn{4}{|c|}{ Men with IHD (N=77) } & \multirow[t]{2}{*}{ P-value a } \\
\hline & $\mathrm{N}$ & $\%$ & Mean & SD & $\mathrm{N}$ & $\%$ & Mean & SD & \\
\hline \multicolumn{10}{|l|}{ Covariates } \\
\hline \multicolumn{10}{|l|}{ Age and technical factors } \\
\hline Age at baseline (years) & - & . & 49.1 & 5.9 & - & . & 52.3 & 5.5 & 0.001 \\
\hline Log of maximum intima media thickness at baseline (log mm) & - & . & -0.013 & 0.19 & - & . & -0.056 & 0.25 & 0.018 \\
\hline \multicolumn{10}{|l|}{ Sonographer at the 11-year follow-up ${ }^{b}$} \\
\hline A & 19 & 3.6 & . & . & 2 & 2.6 & $\cdot$ & . & . \\
\hline B & 6 & 1.1 & . & . & - & . & . & . & . \\
\hline C & 510 & 95.3 & . & . & 75 & 97.4 & $\cdot$ & . & 0.585 \\
\hline Participant in the placebo group of the lipid-lowering drug trial & 37 & 7.0 & $\cdot$ & . & 6 & 7.8 & $\cdot$ & $\cdot$ & 0.778 \\
\hline Participant in the treatment group of the lipid-lowering drug trial & 34 & 6.4 & . & . & 6 & 7.8 & . & . & 0.633 \\
\hline \multicolumn{10}{|l|}{ Biological factors } \\
\hline Blood glucose (mean $\left.{ }^{\mathrm{c}} \mathrm{mmol} / \mathrm{l}\right)$ & - & . & 4.9 & 0.9 & - & . & 4.9 & 0.7 & 0.755 \\
\hline Plasma fibrinogen $\left(\right.$ mean $\left.^{\mathrm{c}} \mathrm{g} / \mathrm{l}\right)$ & - & . & 3.0 & 0.5 & - & . & 3.1 & 0.4 & 0.044 \\
\hline Body mass index at baseline & - & . & 26.5 & 3.2 & - & . & 26.8 & 3.3 & 0.419 \\
\hline Low-density lipoprotein at baseline $(\mathrm{mmol} / \mathrm{l})$ & - & . & 3.8 & 0.9 & - & . & 3.9 & 1.0 & 0.223 \\
\hline High-density lipoprotein at baseline (mmol/l) & - & . & 1.3 & 0.3 & - & . & 1.3 & 0.3 & 0.684 \\
\hline Systolic blood pressure at baseline & - & . & 131.4 & 14.4 & - & . & 127.1 & 14.7 & 0.015 \\
\hline Proportion of follow-up time under lipid-lowering medication & - & . & 0.01 & 0.07 & - & $\cdot$ & 0.04 & 0.14 & 0.059 \\
\hline $\begin{array}{l}\text { Proportion of follow-up time under blood-pressure-lowering } \\
\text { medication }\end{array}$ & - & . & 0.17 & 0.31 & - & . & 0.34 & 0.41 & 0.001 \\
\hline \multicolumn{10}{|l|}{ Behavioral factors } \\
\hline Alcohol consumption (mean ${ }^{\mathrm{c}} \mathrm{g} /$ week) & - & . & 77.6 & 97.1 & - & . & 80.6 & 108.7 & 0.805 \\
\hline \multicolumn{10}{|l|}{ Smoker } \\
\hline No & 203 & 37.9 & . & . & 28 & 36.4 & . & . & . \\
\hline Former & 155 & 29.0 & . & . & 23 & 29.9 & . & . & . \\
\hline Irregular & 40 & 7.5 & . & . & 7 & 9.1 & . & $\cdot$ & . \\
\hline Current & 137 & 25.6 & . & . & 19 & 25.7 & $\cdot$ & $\cdot$ & 0.957 \\
\hline Conditioning leisure-time physical activity (mean ${ }^{c}$ hours/year) & - & . & 118.9 & 99.3 & - & . & 119.4 & 90.7 & 0.968 \\
\hline Cardiorespiratory fitness $\left[\mathrm{ml} \mathrm{O}_{2} /(\mathrm{kg} \cdot \mathrm{min})\right]$ & - & . & 34.2 & 7.0 & - & . & 28.3 & 6.9 & 0.001 \\
\hline \multicolumn{10}{|l|}{ Socioeconomic status } \\
\hline Personal income (meanc 1000 FIM/year) & - & . & 12.0 & 6.7 & - & . & 9.4 & 4.5 & 0.001 \\
\hline \multicolumn{10}{|l|}{ Psychosocial job factors } \\
\hline Social support at work, score & - & . & 6.0 & 2.5 & - & . & 5.7 & 2.4 & 0.245 \\
\hline Index of mental strain at work & - & . & 11.8 & 5.2 & - & . & 13.4 & 5.4 & 0.021 \\
\hline Stress from work deadlines & - & . & 0.35 & 0.48 & - & . & 0.40 & 0.49 & 0.364 \\
\hline \multicolumn{10}{|l|}{ Exposure variables (energy expenditure) } \\
\hline \multicolumn{10}{|l|}{ Absolute measures } \\
\hline Kilocalories per typical workday at baseline & - & . & 2020 & 844 & - & . & 2224 & 842 & 0.048 \\
\hline Total number of kilocalories during the follow-up (in $1000 \mathrm{kcal}$ ) & - & . & 3862 & 2669 & - & . & 2984 & 2415 & 0.012 \\
\hline Kilocalories per 8 hours actually worked during the follow-up & - & . & 1800 & 565 & - & . & 1968 & 642 & 0.013 \\
\hline $\begin{array}{l}\text { Kilocalories per potential 8-hour standard workday during the } \\
\text { follow-up }\end{array}$ & - & . & 1499 & 1028 & - & $\cdot$ & 1167 & 950 & 0.014 \\
\hline \multicolumn{10}{|l|}{ Relative measures } \\
\hline$\% \mathrm{VO}_{2}$ max at baseline & - & . & 28.0 & 11.3 & - & . & 37.8 & 15.5 & 0.001 \\
\hline$\% \mathrm{VO}_{2}$ Res at baseline & - & . & 21.2 & 12.9 & - & . & 31.0 & 17.9 & 0.001 \\
\hline
\end{tabular}

a Difference (t-test or chi-square test).

${ }^{\mathrm{b}}$ All of the ultrasound examinations were performed by the same sonographer at baseline.

${ }^{c}$ Mean of the baseline, 4-year, and 11-year values. 


\section{Appendix B}

\section{Established cardiovascular risk factors, other covariates and change in intima media thickness}

The predictive role of established cardiovascular risk factors and other covariates in the progression of atherosclerosis was determined in the same multiple regression model 4 (fully adjusted) as used in tables 3-6 in the text. All 21 covariates were examined simultaneously in the same model that included occupational exposure measured as the percentage of oxygen reserve at baseline.

In this model, statistically significant associations with the change in the ln-transformed maximum intima media thickness (IMT) were observed for the following variables: age, baseline IMT, participation in the placebo group of an unrelated trial with lipid-lowering medication, proportion of follow-up time under lipid-lowering medication, low-density lipoprotein, systolic blood pressure, and current regular smoking. The remaining 14 covariates, including known predictors of cardiovascular disease such as body mass index, health-enhancing leisure-time physical activity, and plasma fibrinogen, were not statistically significant. Regression coefficients and $\mathrm{P}$-values are shown in the table below.

Associations of covariates with yearly change in the In-transformed maximum IMT during 11-years of follow-up in multiple regression analyses-Kuopio Ischemic Heart Disease Risk Factor Study, 1984-2001 (N=612 men). (IMT = intima media thickness, LDL = low-density lipoprotein, $\mathrm{HDL}=$ high-density lipoprotein, $\mathrm{FIM}=$ Finnish marks, $\% \mathrm{VO}_{2} \mathrm{Res}=$ percent of oxygen uptake reserve)

\begin{tabular}{|c|c|c|}
\hline \multirow[t]{2}{*}{ Variable } & \multicolumn{2}{|c|}{ Multiple regression, adjusted for all covariates ${ }^{a}$} \\
\hline & Coefficient & P-value \\
\hline$\% \mathrm{VO}_{2} \mathrm{Res}$ at baseline & 0.0001437 & 0.010 \\
\hline \multicolumn{3}{|l|}{ Age and technical factors } \\
\hline Age at baseline (years) & 0.0004488 & 0.001 \\
\hline Log of maximum IMT at baseline (log mm) & -0.0369053 & 0.001 \\
\hline \multicolumn{3}{|l|}{ Sonographer at 11-year b } \\
\hline A & Reference & .. \\
\hline B & -0.001138 & 0.740 \\
\hline C & 0.002753 & 0.672 \\
\hline Participant in placebo group of the lipid-lowering drug trial & -0.0057479 & 0.030 \\
\hline Participant in treatment group of the lipid-lowering drug trial & -0.0044867 & 0.096 \\
\hline \multicolumn{3}{|l|}{ Biological factors } \\
\hline Blood glucose (mean $\left.{ }^{\mathrm{c}} \mathrm{mmol} / \mathrm{l}\right)$ & 0.0005984 & 0.442 \\
\hline Plasma fibrinogen $\left(\right.$ mean $\left.^{\mathrm{c}} \mathrm{g} / \mathrm{l}\right)$ & 0.0009593 & 0.521 \\
\hline Body mass index at baseline $\left(\mathrm{kg} / \mathrm{m}^{2}\right)$ & 0.0003933 & 0.091 \\
\hline LDL at baseline (mmol/l) & 0.002578 & 0.001 \\
\hline HDL at baseline (mmol/l) & 0.000036 & 0.988 \\
\hline Systolic blood pressure at baseline $(\mathrm{mm} \mathrm{Hg})$ & 0.0001096 & 0.021 \\
\hline Proportion of follow-up time under lipid-lowering medication & -0.0195729 & 0.018 \\
\hline Proportion of follow-up time under blood-pressure-lowering medication & -0.0010495 & 0.622 \\
\hline \multicolumn{3}{|l|}{ Behavioral factors } \\
\hline Alcohol consumption (mean ${ }^{\mathrm{c}} \mathrm{g} /$ week) & $<0.000001$ & 0.807 \\
\hline \multicolumn{3}{|l|}{ Smoker } \\
\hline No & Reference & .. \\
\hline Former & 0.0015745 & 0.314 \\
\hline Irregular & 0.0024094 & 0.341 \\
\hline Current & 0.0079882 & 0.001 \\
\hline Conditioning leisure-time physical activity (mean c hours/year) & 0.000003 & 0.687 \\
\hline Cardiorespiratory fitness $\left[\mathrm{ml} \mathrm{O}_{2} /(\mathrm{kg} \cdot \mathrm{min})\right]$ & 0.0000849 & 0.477 \\
\hline \multicolumn{3}{|l|}{ Socioeconomic status } \\
\hline Personal income (mean c FIM per year) & -0.0000381 & 0.720 \\
\hline \multicolumn{3}{|l|}{ Psychosocial job factors } \\
\hline Social support at work (mean ${ }^{c}$ ) & -0.0001455 & 0.597 \\
\hline Mental strain at work index (meanc) & -0.0001437 & 0.259 \\
\hline Stress from work deadlines & 0.0005689 & 0.686 \\
\hline Model constant & 0.0222894 & 0.001 \\
\hline
\end{tabular}

a Multiple linear regression with the $\% \mathrm{VO}_{2}$ Res and all covariates listed in this table entered simultaneously into one model.

${ }^{b}$ All ultrasound examinations were performed by the same sonographer at baseline.

c Mean of baseline, 4-year, and 11-year values. 